\title{
La burbuja residencial en Europa (2000-2015). Dimensión y tipos
}

\author{
Jordi Bosch Meda
}

Universitat Politècnica de Catalunya. Departamento de Tecnologia de la Arquitectura

jordi.bosch@hotmail.es

\section{Resumen}

El objetivo de este artículo es identificar aquellos países del Espacio Económico Europeo que, a lo largo del periodo 2000-2015, sufrieron una burbuja residencial y clasificarlos en función de la evolución de los fundamentales durante el periodo alcista mediante el análisis de conglomerados. Según criterios del Fondo Monetario Internacional, dos de cada tres países europeos sufrieron una burbuja residencial en este periodo, con una pérdida de valor desde el pico del $38 \%$ en promedio. Por su parte, el análisis de clústeres revela la existencia de tres tipos de burbujas residenciales en Europa en este periodo: uno que englobaría a todos los países postcomunistas del centro y del este de Europa; otro formado por Irlanda, Grecia, Islandia, España, Chipre, Italia y Malta, y un tercero constituido por Dinamarca, Holanda y Reino Unido.

Palabras clave: vivienda; burbuja residencial; precio de la vivienda; mercado residencial; política de vivienda

Resum. La bombolla residencial a Europa (2000-2015). Dimensió i tipus

L'objectiu d'aquest article és identificar aquells països de l'Espai Econòmic Europeu que, al llarg del període 2000-2015, van patir una bombolla residencial i classificar-los en funció de l'evolució dels fonamentals durant el període alcista mitjançant l'anàlisi de conglomerats. Segons criteris del Fons Monetari Internacional, dos de cada tres països europeus van patir una bombolla residencial en aquest període, amb una pèrdua mitjana de valor des del pic del 38\%. D'altra banda, l'anàlisi de clústers revela l'existència de tres tipus de bombolles residencials a Europa en aquest període: un que englobaria tots els països postcomunistes del centre i de l'est d'Europa; un altre que estaria format per Irlanda, Grècia, Islàndia, Espanya, Xipre, Itàlia i Malta, i un altre de constituït per Dinamarca, Holanda i Regne Unit.

Paraules clau: habitatge; bombolla residencial; preu de l'habitatge; mercat residencial; política d'habitatge 
Résumé. La bulle du logement en Europe (2000-2015) : dimension et types

Le but de cet article est d'identifier les pays de l'Espace Économique Européen (EEE) qui ont connu une bulle du logement au cours de la période 2000-2015, et de les classer en fonction de l'évolution des fondamentaux pendant la période de hausse du marché grâce à l'analyse de cluster. Selon les critères du Fonds Monétaire International, deux pays de l'EEE sur trois ont connu une bulle du logement dans cette période, avec une perte moyenne de valeur de 38\% depuis le pic. L'analyse de cluster révèle l'existence de trois types de bulles du logement en Europe lors de cette période : l'une qui comprend tous les pays post-communistes d'Europe centrale et orientale ; l'autre formée par Irlande, la Grèce, l'Islande, l'Espagne, Chypre, l'Italie et Malte ; et une troisième composée par le Danemark, les Pays-Bas et le Royaume-Uni.

Mots-clés: logement; bulle du logement; prix du logement; marché du logement; politique du logement

Abstract. The housing bubble in Europe (2000-2015): Dimension and types

The aim of this article is to identify the European Economic Area (EEA) countries that experienced a housing bubble during the period 2000-2015; and classify them according to the evolution of the fundamentals of house prices during the rising phase through cluster analysis. According to International Monetary Fund criteria, two out of three EEA countries experienced a housing bubble in this period, and the price corrections during housing price bust averaged 38\%. The cluster analysis indicates the existence of three types of housing bubbles in Europe during this period: one encompasses all post-communist EEA countries from Central and Eastern Europe; a second one consisting of Ireland, Greece, Iceland, Spain, Cyprus, Italy and Malta; and a third one composed by Denmark, the Netherlands and the United Kingdom.

Keywords: housing; housing bubble; housing price; housing market; housing policy

\section{Sumario}
1. Introducción
4. Resultados
2. Marco teórico
5. Conclusiones y discusión
3. Metodología
Referencias bibliográficas

\section{Introducción}

A finales del siglo XX, el precio de la vivienda empezó a subir con fuerza en la mayoría de países europeos. Por lo general, esta tendencia alcista se mantuvo en niveles muy elevados hasta la llegada de la crisis económica y financiera. Con ella, el ciclo se invirtió y los activos residenciales empezaron a desvalorizarse en casi todos los países a partir del año 2008 (André, 2010; Scatigna et al., 2014; Ciarlone, 2015; Knoll et al., 2017).

Esta sincronización de los mercados europeos de vivienda fue consecuencia, sobre todo, de la creciente globalización financiera y de la interdependencia 
económica entre países, de la atribución en 1999 de la política monetaria de la zona euro al Banco Central Europeo, y, por supuesto, de las sucesivas ampliaciones de la Unión Europea (Ahearne et al., 2005; Ahrend et al., 2008; Kim y Renaud, 2009; Taylor, 2009; Backé et al., 2010; Hessel y Peeters, 2011; Loutskina y Strahan, 2015; Lee y Lee, 2017).

En este contexto, el objetivo de la presente investigación es doble: identificar aquellos países de Europa que, a lo largo del periodo 2000-2015, sufrieron una burbuja residencial y clasificarlos a partir de la evolución de los principales indicadores demográficos, macroeconómicos, financieros, de producción residencial y de política de vivienda que más directamente influyen en la formación de los precios residenciales.

Las principales aportaciones de este estudio al marco teórico existente son fundamentalmente dos: en primer lugar, ofrece una visión completa y actualizada de la burbuja residencial en Europa, ya que engloba la práctica totalidad de los países del continente, mientras que la mayoría de trabajos similares se limitan a un reducido número de ellos; $\mathrm{y}$, en segundo lugar, incluye variables de política de vivienda entre los factores determinantes analizados, aspecto este apenas considerado en investigaciones anteriores.

Esperamos que los resultados obtenidos puedan contribuir a reducir la separación existente entre trabajos teóricos y empíricos en este campo (Madrid y Hierro, 2015), y a perfeccionar los diferentes modelos econométricos de detección de burbujas residenciales. Como subrayan Dieci y Westerhoff (2016), gran parte de las modelizaciones que pretenden explicar las dinámicas de los precios residenciales fueron diseñadas originariamente para productos financieros, por lo que parten de premisas que no se cumplen en los mercados de vivienda (p. ej.: hipótesis de mercados eficientes, existencia de información perfecta o comportamiento racional de los actores). Además, conviene recordar que la vivienda tiene unas particularidades que la hacen diferente de los activos financieros, como el carácter único del suelo sobre el cual se levanta, la confluencia en el mismo bien de una necesidad básica (bien de primera necesidad) y de uno de inversión (en muchos casos, el activo más valioso de las familias) o los largos periodos de tiempo requeridos para su producción a causa de la escasa industrialización del sector de la construcción, así como los largos trámites que usualmente preceden al otorgamiento de licencia (Algieri, 2013; Levitin y Wachter, 2013).

El artículo se estructura del siguiente modo: tras este primer apartado introductorio, el segundo sintetiza el marco teórico existente sobre burbujas residenciales, el tercero expone la metodología seguida, el cuarto muestra los resultados de la investigación y, por último, el artículo concluye con una síntesis y una discusión de los mismos.

\section{Marco teórico}

\subsection{Las burbujas residenciales: concepto y tipos}

En términos económicos, una burbuja residencial suele definirse como el aumento intenso y continuado del precio de la vivienda sin relación alguna 
con la evolución de sus fundamentales (Crowe et al., 2013), es decir, con los elementos que determinan los precios. Esta sobrevaloración, a medio-largo plazo, tiende a corregirse, bien mediante una lenta disminución de precios (se desinfla) o bien con una drástica y rápida caída del valor (explota).

Según las causas que generan tal proceso, las burbujas pueden ser irracionales o racionales. Las primeras, como su nombre indica, se explican por un comportamiento irracional de los compradores, en manada o rebaño (Lux, 1995), replicando el comportamiento de los otros sin más, como si entrar en el mercado residencial fuera una norma social institucionalizada (Levine y Zajac, 2007). En cambio, las racionales son aquellas en las que el aumento del precio responde a expectativas racionales (aunque quizás no ciertas) de futuros beneficios, de modo que el precio final es la suma del presente valor teórico según los fundamentales más la actualización de la futura revalorización, lo que provoca su desviación respecto al valor fundamental (Craine, 1993: 4; Hilbers et al., 2008: 39; Brunnermeier y Oehmke, 2013: 1231-1233; Scherbina, 2013).

Estas burbujas racionales, también conocidas como especulativas, pueden ser explosivas o intrínsecas. En las primeras, los factores causantes son extrínsecos al activo (Black et al., 2006), mientras que las intrínsecas se generan por meras expectativas favorables o sobrerreacción a la evolución prevista de los fundamentales, en particular, de los rendimientos (Froot y Obstfeld, 1991). En los análisis de estos tipos de burbujas residenciales, las rentas del alquiler adquieren una gran importancia, ya que a partir de estas puede deducirse el valor fundamental de la vivienda (Poterba, 1992; Himmelberg et al., 2005; Nneji et al., 2013).

\subsection{Los factores determinantes en la formación de los precios residenciales}

Los principales factores que determinan la formación de los precios residenciales pueden clasificarse en tres grupos: los relacionados con la demanda, los relacionados con la oferta y aquellos de tipo transversal.

\section{Factores de la demanda}

El comportamiento de la demanda responde mayormente a dos variables: los ingresos disponibles y la evolución demográfica, en particular, la formación y la destrucción de hogares (Case y Shiller, 2003).

Respecto al primer factor, la literatura es casi unánime: las fluctuaciones al alza o a la baja de los ingresos disponibles repercuten en el mismo sentido en el volumen de demanda y en los precios residenciales (Holly y Jones, 1997; Capozza et al., 2002; Black et al., 2006; Arshanapalli y Nelson, 2008; Gattini y Hiebert, 2010).

Respecto al segundo, el modelo de oferta y demanda agregadas sostiene que un aumento de la demanda (en nuestro caso, de vivienda por crecimiento demográfico) crea tensiones inflacionistas, lo que sitúa el nuevo equilibrio en un punto de la oferta agregada a mayores precios. Sin embargo, la evidencia existente no es concluyente. Algunos estudios defienden el gran impacto del 
crecimiento demográfico en el incremento de los activos residenciales (Jud y Winkler, 2002; Catte et al., 2004; Terrones y Otrok, 2004). Helbling y Terrones (2003) estiman que un crecimiento demográfico del 1\% genera incrementos del precio del 4\%. Capozza et al. (2002), a partir de la dinámica de precios de las 62 áreas metropolitanas norteamericanas entre 1979-1995, calculan que, a largo plazo, el mismo incremento poblacional genera un aumento del precio de la vivienda del 1,5\%. Pero, por el contrario, otros relativizan el impacto del componente demográfico. Hilbers et al. (2008), tras estudiar el precio de la vivienda en Europa entre 1986-2006, concluyeron que el comportamiento del mercado mantenía poca relación con los factores demográficos. No obstante, la investigación de Cvijanovic et al. (2010) sobre el impacto de la demografía en los precios residenciales en Estados Unidos aportó nuevas perspectivas. Tras desglosar el crecimiento demográfico en sus componentes básicos (crecimiento natural e inmigración), detectaron que solo la inmigración era capaz de predecir incrementos de precio, sobre todo en áreas urbanas particularmente densas. En cambio, otros subrayan la necesidad de que exista un contexto de oferta de vivienda inelástica para que el crecimiento demográfico presione el precio al alza (Glaeser et al., 2008; Davidoff, 2013). En suma, es probable que el efecto de la presión demográfica en los precios esté condicionado tanto por la intensidad del incremento de la demanda como por otras variables fundamentales.

\section{Factores de la oferta}

La elasticidad de la oferta residencial es la capacidad que tiene un sistema de vivienda para adecuar los niveles de provisión de la misma a la demanda. La producción de nueva vivienda requiere de un tiempo de construcción que difícilmente es inferior a dos años (Glaeser et al., 2008: 5), lo cual implica asumir la existencia de un grado de inelasticidad intrínseco a la vivienda que puede agravarse por limitaciones de suelo urbanizado, mano de obra o industria especializada (Hilbers et al., 2008).

La relación entre la elasticidad de la oferta residencial y el comportamiento de los precios es un tema aún no resuelto. A pesar de que numerosos autores afirman que las mejoras en la elasticidad de la oferta ayudan a moderar la tendencia alcista de los precios en periodos de fuerte demanda y, a la inversa (Malpezzi y Wachter, 2005; Glaeser y Gyourko, 2006; Grimes y Aitken, 2010; Van Nieuwerburgh y Weill, 2010), existe una amplia evidencia de burbujas especulativas en mercados residenciales con ofertas muy elásticas (Glaeser et al., 2008).

\section{Factores transversales}

Los factores transversales más importantes son: la política monetaria, en concreto, los tipos de interés, la cantidad de crédito disponible y la facilidad para acceder al mismo; la situación económica, y la política de vivienda, incluyendo en esta la fiscal relacionada con el sector residencial.

Los tipos de interés determinan los costes de financiación, de modo que cuando son bajos se incentiva la inversión en vivienda por parte de promotores, 
constructores y particulares. Lógicamente, una política expansiva de bajos tipos de interés, para que sea efectiva, debe ir acompañada de facilidades en el acceso al crédito y de liquidez suficiente. Existe una vasta evidencia empírica de la relación entre aumento de los precios residenciales y bajos tipos de interés y, de modo opuesto, del enfriamiento de los mercados cuando los tipos suben y las condiciones para acceder al crédito se endurecen (Agnello y Schuknecht, 2011). De hecho, numerosos autores consideran que unos tipos de interés bajos son un requisito imprescindible para la formación de burbujas residenciales (Tirole, 1985; Grossman y Yanagawa, 1993; Himmelberg et al., 2005; Madrid y Hierro, 2015).

La situación económica se relaciona con todos los factores mencionados: condiciona la capacidad económica de la demanda vía ingresos y empleo, las variaciones de la demanda por su incidencia en los movimientos migratorios, y la elasticidad de la oferta por su repercusión en la capacidad y en el interés de los promotores en invertir. Además, constituye un elemento psicológicocolectivo esencial para los comportamientos en rebaño. No obstante, cuando el mercado de la vivienda se encuentra en expansión actúa como un motor económico y, por contra, se convierte en un lastre cuando se estanca, por lo que no solo la evolución de la actividad económica influye en la vivienda, sino que también, en sentido inverso, el sector residencial acaba incidiendo en el crecimiento económico (Helbling y Terrones, 2003; Leamer, 2007). Por ello, la evolución del precio de la vivienda y, por extensión, la del sector residencial está fuertemente relacionada con la actividad económica (Valadez, 2011).

La política de vivienda constituye otro elemento clave. Los objetivos de la actuación pública en este campo, así como el alcance de las medidas implementadas determinan la actuación de todos los actores. Uno de los aspectos más importantes es el fomento de la vivienda en propiedad, bien a través de medidas fiscales (desgravaciones), bien mediante ayudas económicas directas, bien de forma indirecta como consecuencia de un exiguo desarrollo de la vivienda de alquiler social y del sistema de ayudas al pago del alquiler. Uno de los escasos trabajos que ha puesto de relieve su importancia en la formación de la burbuja es el de Algieri (2013). Tras estudiar los mercados residenciales de Alemania, Francia, Italia, España, Holanda, Reino Unido y Estados Unidos desde 1970 hasta 2010, Algieri (2013) detectó que, además de elementos como los ingresos reales, los tipos de interés y la inflación, existía un componente que desempeñaba un papel decisivo en la evolución del precio: los cambios estructurales en los mercados y en las preferencias de los hogares a causa de la intervención del gobierno, por ejemplo, mediante el fomento de la propiedad.

\subsection{Métodos de análisis, detección y clasificación de burbujas}

La mayoría de estudios matemático-cuantitativos sobre burbujas residenciales pueden clasificarse en dos grupos: aquellos cuyo propósito es la detección y la cuantificación de la burbuja y aquellos cuya finalidad es la clasificación de territorios o de periodos de tiempo en función de la evolución de los mercados. 
El primer grupo, el cual aglutina la mayor parte de la investigación empírica sobre burbujas especulativas, se basa en técnicas econométricas que, en muchos casos, han sido diseñadas originariamente para el análisis de activos financieros. Una de ellas es el denominado test del límite de la varianza (Leroy y Porter, 1981; Shiller, 1981). Otro es el test de cointegración (Campbell y Shiller, 1987; Diba y Grossman, 1988), probablemente el más empleado en vivienda (Arshanapalli y Nelson, 2008; Mikhed y Zemč́k, 2009; Gattini y Hiebert, 2010; Gerdesmeier et al., 2012). Otros dos son el denominado test de West (1987) y el test de rachas o de supervivencia (McQueen y Thorley, 1994; Cunningham y Kolet, 2011). Y, por último, existe una batería de investigaciones basadas en regresiones (Tsatsaronis y Zhu, 2004; Machado y Sousa, 2006; McMillen, 2008; Zietz et al., 2008; Posedel y Vizek, 2009).

Respecto al segundo grupo de estudios, el volumen de investigaciones es mucho más reducido y básicamente descansa sobre las técnicas estadísticas disponibles de clasificación por grupos. En esta línea, Leung et al. (2008) empleó el método de análisis por clústeres mediante la metodología de K-medias para estructurar la evolución del mercado inmobiliario en Hong Kong entre los años 1996 y 2008 en periodos de sobrevaloración e infravaloración. Lily et al. (2012) también aplicaron dicha técnica para examinar el mercado inmobiliario en Singapur en el periodo 1996-2010. Haynes et al. (2010) usaron el análisis por clústeres para estudiar la formación de la burbuja residencial en las principales ciudades norteamericanas entre 2008 y 2014. Antoniucci y Marella (2016) emplearon la metodología de la regresión multivariable y el análisis de clústeres sobre el comportamiento de los precios entre 2008 y 2014 en las principales ciudades italianas para conocer el impacto de la crisis en estos mercados. Azevedo et al. (2016) también recurrieron al análisis de clústeres para clasificar los sistemas de vivienda europeos a partir de los resultados de la encuesta europea sobre ingresos y condiciones de vida (EU-SILC) de 2009. Esta investigación se enmarca en este segundo grupo de trabajos.

\subsection{Explicaciones a la burbuja residencial de los años 2000}

A pesar de que no existe un consenso unánime sobre los factores que desencadenaron la burbuja residencial de los años 2000 en Europa, la mayor parte de las explicaciones giran alrededor de cinco motivos: unos tipos de interés excesivamente bajos, el gran excedente de liquidez, la generalización de unas políticas de vivienda orientadas a promover la propiedad, el factor meramente especulativo y la inelasticidad de la oferta residencial. Además, para poder entender el comportamiento de los mercados de vivienda de los países postcomunistas, numerosos autores reconocen la existencia de circunstancias específicas.

\section{Los bajos tipos de interés}

Es ampliamente aceptado que a principios del siglo XXI los bancos centrales de los países desarrollados, para reactivar la economía, mantuvieron los tipos de 
interés a unos niveles excesivamente bajos durante demasiado tiempo, incluso por debajo de la inflación en determinados momentos, lo que propició la especulación en los mercados en alza (Ahearne et al., 2005; Ahrend et al., 2008; Taylor, 2009). Por ello, muchas investigaciones coinciden en que uno de los principales responsables de la burbuja residencial en Estados Unidos fue la Reserva Federal (Del Negro y Otrok, 2007; Jarocinski y Smets, 2008; Hubbard y Mayer, 2009; Iacoviello y Neri, 2010; Bryant y Kohn, 2013), y, en Europa, el Banco Central Europeo (BCE), la institución responsable de la política monetaria en la zona euro y el actor más influyente en la coordinación de las políticas monetarias entre países comunitarios (Ahearne et al., 2005; Ahrend et al., 2008; Taylor, 2009; Hessel y Peeters, 2011). Sin embargo, debido a la existencia de otras variables, no todos los países de la zona euro fueron igual de sensibles a la política monetaria del BCE (Hilbers et al., 2008). Seyfried (2010) sostiene que estas fueron adecuadas para Francia y Alemania, pero excesivamente laxas para Irlanda y España, lo que favoreció la formación de sus burbujas residenciales.

\section{La liquidez del sistema}

Los años de expansión estuvieron marcados por una gran liquidez. La progresiva desregularización del sistema financiero iniciada en la década de los ochenta y, en cierto modo, completada en los noventa (Ahearne et al., 2005; Agnello y Schuknecht, 2011) permitió a las entidades financieras asumir mayores riesgos, tanto de forma directa mediante la reducción de los requisitos para acceder al crédito, como de forma indirecta a través de la comercialización de nuevos productos financieros (Torrero, 2008; Duca et al., 2010). Ello provocó una expansión global del crédito que, en gran medida, se dirigió al sector residencial atraído por sus expectativas de revalorización (Andrews et al., 2011). En su estudio sobre el comportamiento de los mercados residenciales de 18 países industrializados entre 1980 y 2007, Agnello y Schuknecht (2011) destacan la importancia de la liquidez en contextos de bajos tipos de interés en la probabilidad de formación y estallido de burbujas residenciales. De igual modo, numerosos autores atribuyen al desarrollo de nuevas formas de financiación hipotecaria gran parte del aumento del precio de la vivienda en países como Holanda (IMF, 2014) o Dinamarca (Dam et al., 2011), es decir, en aquellos en los que la deuda hipotecaria de los hogares, medida en porcentaje del producto interior bruto (PIB), alcanzó en 2008 los valores más elevados de toda Europa.

\section{El fomento de la propiedad}

Desde mediados de los años ochenta hasta el estallido de la burbuja, los sistemas de vivienda europeos experimentaron un aumento sostenido de las tasas de propiedad (Scanlon y Whitehead, 2004; Andrews et al., 2011: 17). Este creciente interés por la propiedad vino propiciado por una fiscalidad favorable (Laino y Pittini, 2011: 11); por el aumento de la capacidad económica de la demanda (Andrews et al., 2011; Andrews y Caldera, 2011); por la privati- 
zación del parque de alquiler social, en especial, en los países excomunistas (Laino y Pittini, 2011: 12), y por una progresiva reducción del alcance de la política de vivienda en toda Europa, ya que a medida que la intervención del Estado en este campo se reduce, la vivienda en propiedad resulta más atractiva por su estabilidad, seguridad y protección frente a futuros vaivenes del mercado. Numerosos autores señalan que este fomento de la propiedad fue uno de los principales causantes de la burbuja residencial, tanto en Estados Unidos como en Europa (Wallison, 2009; Schwartz y Seabrooke, 2009; Sowell, 2009; Clark, 2013).

\section{La especulación}

Por supuesto, el componente especulativo, a saber, las expectativas de revalorización del bien, está presente en los estudios sobre los causantes de la burbuja (Shiller, 2005; Brunnermeier y Julliard, 2008). Mayer y Hubbard (2009), tras examinar las fuertes tensiones inflacionistas de los mercados de la vivienda de Australia, Irlanda, España, Reino Unido y Estados Unidos, llegaron a la conclusión de que, más allá de factores como el crecimiento económico o de regulaciones demasiado laxas, el componente especulativo era fundamental.

\section{La inelasticidad de la oferta residencial}

Los estudios sobre la inelasticidad de la oferta residencial como factor coadyuvante de la escalada del precio de la vivienda en los años 2000 son limitados y, en la mayoría de casos, se circunscriben al contexto estadounidense (Glaeser et al., 2008; Huang y Tang, 2012). En Europa, las alusiones a la inelasticidad de la provisión residencial suelen emplearse solo para determinados países, en particular para los postcomunistas del centro y el este de Europa (Egert y Mihaljek, 2007a, 2007b; Roy, 2008), así como para Holanda (Hoeller y Rae, 2007; Vermeulen y Rouwendal, 2007; Cunha et al., 2008; Fortune y Moohan, 2008; Caldera y Johansson, 2013; IMF, 2014), Reino Unido (Barker, 2006; Fortune y Moohan, 2008; Muellbauer y Murphy, 2008; Niemietz, 2012; Caldera y Johansson, 2013; Chandler y Disney, 2014) o Dinamarca (Hoeller y Rae, 2007; Fortune y Moohan, 2008).

\section{El caso particular de los países postcomunistas}

Además de los motivos anteriores, la evolución alcista de la vivienda en los países postcomunistas del centro y del este de Europa estuvo alentada, en gran medida, por tres factores específicos: el desarrollo jurídico e institucional que experimentaron sus mercados residenciales a partir del año 2000, en particular, en materia hipotecaria (Shelburne y Palacin, 2006; Égert y Mihaljek, 2007a, 2007b); la infravaloración que sufría la vivienda a causa del control estatal del periodo comunista (Égert y Mihaljek, 2007a, 2007b), y el incremento de los ingresos disponibles debido, en buena parte, a las crecientes remesas de dinero de los trabajadores emigrados (Shelburne y Palacin, 2006; Égert y Mihaljek, 2007a; Stepanyan et al., 2010; Huynh-Olesen et al., 2013). 


\section{Metodología}

\subsection{Ambito territorial y temporal}

La investigación engloba a los países que constituyen el Espacio Económico Europeo (EEE) excepto Rumanía y Liechtenstein, por la imposibilidad de compilar información de estos en todas las variables consideradas. Por consiguiente, se realiza sobre un total de 28 países: Noruega, Islandia y los 27 que formaban la Unión Europea (UE) a finales de 2012 excepto Rumanía. El interés de acotar el trabajo al EEE responde a dos motivos: estos países, por un lado, representan la casi totalidad de Europa en términos de población y territorio y, por otro, comparten aspectos económico-financieros que resultan determinantes para la formación de los precios residenciales. Conviene tener presente tres aspectos:

1. Que el funcionamiento del sistema hipotecario del EEE se encuentra fuertemente condicionado por la política monetaria del BCE y la legislación comunitaria relacionada.

2. Que existe libre circulación de servicios y capitales entre los países del EEE, lo que ha provocado una creciente expansión y homogeneización de la oferta bancaria e hipotecaria en todo el EEE.

3. Todos ellos deben desarrollar políticas vinculadas al principio del mercado único (respecto a la influencia de la política monetaria y la liquidez del sistema financiero en los precios residenciales, véase los apartados 2.2 y 2.4 del marco teórico).

El ámbito temporal de la investigación comprende el periodo 2000-2015. La elección del límite inicial del año 2000 se debe a que la convergencia alcista de los mercados residenciales europeos se produjo mayoritariamente a partir de 2001, pues, tras el derrumbe de los valores tecnológicos en la bolsa en 2001, el sector inmobiliario atrajo a muchos inversores (Shiller, 2005; Andrews et al., 2011). Por su parte, el establecimiento del límite final en 2015 responde a dos motivos: es el último año del que se disponen datos, y en todos los países afectados por la burbuja, excepto en Grecia e Italia, el periodo deflacionista ya había concluido a finales de 2015.

\subsection{Métodos empleados}

Para identificar los países europeos que a lo largo del periodo 2000-2015 sufrieron una burbuja residencial hemos aplicado el criterio del Fondo Monetario Internacional (FMI), según el cual, para que pueda considerarse la existencia de una burbuja en el mercado residencial, los precios deben caer más de un 14\% desde su valor máximo (Helbling y Terrones, 2003: 63).

Para su clasificación, hemos utilizado el análisis de clústeres o conglomerados mediante el programa SPSS (Statistical Package for the Social Sciences). Esta técnica es particularmente idónea para el propósito de la investigación, 
ya que tiene como finalidad formar grupos con un elevado grado de homogeneidad interna y de heterogeneidad externa a partir de unas variables determinadas. En primer lugar, dado que las variables están en escalas diferentes, las hemos estandarizado mediante el método de puntuaciones $\mathrm{Z}$. En segundo lugar, hemos empleado el procedimiento jerárquico siguiendo el método aglomerativo del vecino más lejano y usando la distancia euclídea al cuadrado en los datos del intervalo. Con ello hemos determinado el número de conglomerados en 3 grupos (figura 1). Posteriormente, mediante el método no jerárquico de $\mathrm{K}$-medias, con una previsión de 3 grupos, un máximo de mil iteraciones, sin usar medias actualizadas, y con recuperación de casos perdidos (para el caso de Malta, ya que no disponemos de la información completa de este país), hemos comprobado los resultados obtenidos anteriormente mediante el método jerárquico. Conviene subrayar que, de los resultados obtenidos mediante esta metodología, no pueden deducirse relaciones de causalidad entre variables, sino solamente agrupaciones y asociaciones entre las mismas.

\subsection{Variables y fuentes}

La investigación se basa en 21 variables estructuradas en seis dimensiones: precio real de la vivienda, aspectos macroeconómicos, sistema financiero, aspectos demográficos, parque residencial y política de vivienda. Su descripción y sus fuentes de información están especificadas en las tablas 1 y 2 . Para la clasificación por conglomerados, se han empleado un total de 13 variables representativas de los factores que, según el marco teórico, en mayor medida determinaron la formación de los precios residenciales entre los años 2000 y 2008. Estas 13 variables están recogidas en la tabla 2.

Tabla 1. Variables y fuentes de información utilizadas sobre la evolución de los precios residenciales. Europa, 2000-2015

\begin{tabular}{ll}
\hline Variables del precio real de la vivienda & Fuentes \\
\hline Trimestre valor real máximo (pico) & Elaboración propia a partir del índice de precios de \\
Valor real máximo (pico) (a) & consumo armonizado de EUROSTAT (solo aplicado en \\
(año 2000 = base 100) & las bases de precios residenciales nominales); del pre- \\
& cio de la vivienda según la base de datos de la OECD \\
Trimestre valor real mínimo & (Alemania, Austria, Bélgica, Dinamarca, España, Finlan- \\
(postpico) & dia, Francia, Grecia, Holanda, Irlanda, Italia, Portugal, \\
& Reino Unido, Suecia y Eslovenia -a partir de 2007-); \\
Valor real mínimo (b) (postpico) & del BIS (Bank for International Settlements) (Luxem- \\
(año 2000 = base 100) & burgo, Malta, y República Checa -a partir de 2008-); \\
& del Banco Central Europeo (Chipre, Hungría, Lituania, \\
Caída del valor real: - [1 - (b)/(a)] & Letonia y Estonia); del Banco Nacional de Chequia \\
& (República Checa entre 2000-2008); del Banco Nacio- \\
& nal de Eslovaquia (Eslovaquia, solo datos disponibles a \\
& partir de 2002); de la Oficina de Estadística de Polonia \\
& (Polonia); de la Oficina de Estadística de Eslovenia \\
& (Eslovenia - hasta 2008-), y del Instituto Nacional de \\
& Estadística de Bulgaria (Bulgaria). \\
\hline
\end{tabular}


Tabla 2. Variables y fuentes de información sobre aspectos macroeconómicos, financieros, demográficos, del parque residencial y de la política de vivienda utilizados para la clasificación de los países. Europa, 2000-2015

\begin{tabular}{|c|c|}
\hline \multicolumn{2}{|l|}{ Aspectos macroeconómicos } \\
\hline $\begin{array}{l}\text { Valor PIB real per cápita } \\
\text { máximo (año } 2000=\text { base 100) }\end{array}$ & $\begin{array}{l}\text { Elaboración propia a partir de EUROSTAT y datos de la Oficina de Estadística de } \\
\text { Islandia (Islandia). }\end{array}$ \\
\hline $\begin{array}{l}\text { Ingresos netos disponibles máximos } \\
\text { por habitante en PPA } \\
\text { (año } 2000=\text { base } 100 \text { ) }\end{array}$ & Elaboración propia a partir de EUROSTAT. \\
\hline \multicolumn{2}{|l|}{ Sistema financiero } \\
\hline Deuda hipotecaria 2000 (\% PIB) (a) & $\begin{array}{l}\text { Elaboración propia a partir de European Mortgage Federation (EMF, 2009, 2010, } \\
\text { 2012). }\end{array}$ \\
\hline Deuda hipotecaria 2008 (\% PIB) $(b)$ & Nota: \\
\hline & Datos de Chequia, Finlandia y Eslovaquia correspondientes a 2002 y 2008. \\
\hline $\begin{array}{l}\text { Tipo de interés hipotecario real } \\
\text { (media anual 2000-2008) }\end{array}$ & $\begin{array}{l}\text { Elaboración propia a partir del: índice de precios de consumo armonizado de } \\
\text { EUROSTAT, y European Mortgage Federation (EMF, 2009, 2010, 2012). }\end{array}$ \\
\hline \multicolumn{2}{|l|}{ Aspectos demográficos } \\
\hline Población año $2008(2000$ = 100) & Elaboración propia a partir de EUROSTAT. \\
\hline \multicolumn{2}{|l|}{ Oferta y parque residencial } \\
\hline $\begin{array}{l}\text { Viviendas construidas 2000-2008 } \\
\text { (media anual del número de } \\
\text { viviendas x } 1.000 \text { habitantes) }\end{array}$ & $\begin{array}{l}\text { Elaboración propia a partir de: European Mortgage Federation (EMF, 2009, 2010, } \\
\text { 2012) y datos de población de Eurostat. }\end{array}$ \\
\hline Tasa de vivienda en propiedad (2000) & $\begin{array}{l}\text { Elaboración propia a partir de: Sak y Raponi (2001) (Chequia, Dinamarca, Grecia, } \\
\text { Irlanda, Luxemburgo, Reino Unido); Federcasa (2006) (Bélgica, Chequia, Chipre, } \\
\text { Eslovaquia, España, Finlandia, Francia, Grecia, Holanda, Hungría, Letonia, Lituania, } \\
\text { Malta, Polonia y Portugal); Dol y Haffner (2010) (Austria, Bélgica, Chequia, Eslova- } \\
\text { quia, España, Grecia, Hungría, Letonia, Lituania, Luxemburgo, Polonia y Portugal); } \\
\text { Domanski y Norris (2009) (Bélgica, Chequia, Chipre, Eslovenia, España, Finlandia, } \\
\text { Francia, Grecia, Hungría, Letonia, Lituania, Luxemburgo, Polonia, Portugal y Reino } \\
\text { Unido); Hussar (2014) (Estonia); EMF (2009) (Bulgaria); datos de la Oficina de } \\
\text { Estadística de Italia (Italia); datos de la Oficina de Estadística de Noruega (Noruega); } \\
\text { datos de la Oficina de Estadística de Suecia (Suecia); Scanlon y Whitehead (2004) } \\
\text { (Alemania); Ruonavaara (2012) (Islandia), y Karlberg y Victorin (2004: 58) (Dinamar- } \\
\text { ca, Finlandia e Islandia). } \\
\text { Notas: } \\
\text { 1. Un país puede tener atribuidas dos o más fuentes de información si el dato de } \\
\text { estas es coincidente. } \\
\text { 2. En Noruega y Suecia la vivienda cooperativa no se incluye en el cómputo de la } \\
\text { vivienda en propiedad. } \\
\text { 3. Datos de Grecia correspondientes a 1999. } \\
\text { 4. Datos de Alemania, Chipre, Eslovaquia, Italia, Luxemburgo, Noruega y Suecia } \\
\text { correspondientes al año 2001. } \\
\text { 5. Datos de Malta correspondientes a 2002. }\end{array}$ \\
\hline
\end{tabular}


Tabla 2. Variables y fuentes de información sobre aspectos macroeconómicos, financieros, demográficos, del parque residencial y de la política de vivienda utilizados para la clasificación de los países. Europa, 2000-2015 (continuación)

Tasa de vivienda en propiedad (2008) Elaboración propia a partir de: Laino y Pittini (2011) (Alemania, Austria, Bélgica, Bulgaria, Dinamarca, Eslovaquia, Eslovenia, España, Estonia, Finlandia, Holanda, Hungría, Irlanda, Italia, Letonia, Malta, Portugal y Reino Unido); Hegedus et al. (2013) (Chequia y Polonia); EMF (2009) (Grecia, Lituania y Luxemburgo); EMF (2010) (Estonia, Lituania y Luxemburgo); EMF (2012) (España y Francia); Dol y Haffner (2010) (Bélgica, Dinamarca, Estonia, España, Finlandia y Malta); la base de datos de la OECD (Housing Markets and Structural Policies in OECD countries) (Suecia); Pittini et al. (2015) (Chipre); datos de la Oficina de Estadística de Noruega (Noruega), y datos de la Oficina de Estadística de Islandia (Islandia).

Notas:

1. Un país puede tener atribuidas dos o más fuentes de información si el dato de estas es coincidente.

2. Datos de Dinamarca, Polonia y Suecia correspondientes a 2009.

3. Datos de Chipre y Noruega correspondientes a 2011.

4. En Noruega y Suecia la vivienda cooperativa no se incluye en el cómputo de la vivienda en propiedad.

Política de vivienda

Tasa de vivienda social (año 2000) Elaboración propia a partir de: Federcasa (2006) (Alemania, Austria, Bélgica, Chipre, Dinamarca, Eslovaquia, Eslovenia, España, Estonia, Finlandia, Francia, Grecia, Holanda, Hungría, Irlanda, Italia, Letonia, Lituania, Luxemburgo, Noruega, Polonia, Portugal, Reino Unido y Suecia); Norris y Shiels (2004) (Chequia y Bulgaria); Scanlon y Whitehead (2004) (Islandia); Planning Authority (2002) (Malta); Crook y Kemp (2014: 129).

Notas:

1. Un país puede tener atribuidas dos o más fuentes de información si el dato de estas es coincidente.

2. Datos de Italia y Francia correspondientes a 1999.

3. Datos de Austria, Bélgica, Chequia, Eslovaquia, Finlandia, Luxemburgo, Malta y Reino Unido correspondientes a 2001.

4. Datos de Alemania, Bulgaria, Eslovenia, Polonia y Portugal correspondientes a 2002.

5. Datos de Chipre, España, Estonia, Holanda, Hungría, Islandia, Letonia y Lituania correspondientes a 2003.

Tasa de vivienda social (año 2008)

Elaboración propia a partir de: Laino y Pittini (2011) (Alemania, Austria, Bélgica, Bulgaria, Dinamarca, Eslovaquia, Eslovenia, España, Estonia, Finlandia, Francia, Grecia, Holanda, Hungría, Irlanda, Italia, Letonia, Lituania, Luxemburgo, Malta, Portugal, Reino Unido y Suecia); Hegedus et al. (2013: 72) (Chequia, Hungría y Polonia); Scanlon et al. (2015) (Suecia); Czischke y Pittini (2007) (Chipre); Andersen (2012) (Noruega), y Sveinsson (2010: 54) (Islandia).

Notas:

1. Un país puede tener atribuidas dos o más fuentes de información si el dato de estas es coincidente.

2. Datos de Noruega correspondientes a 2004.

3. Datos de Chipre correspondientes a 2005.

4. Datos de Letonia correspondientes a 2010.

Gasto público medio anual en protección social en vivienda (en \% PIB) (2000-2008)

Gasto público medio anual en ayudas al pago del alquiler (en \% PIB) (2000-2008)
Elaboración propia a partir de EUROSTAT (ESSPROS). Esta fuente de información de ámbito europeo nos permite conocer los recursos públicos que cada país destina a protección social en materia de vivienda, entendidos como el sumatorio de tres conceptos: las ayudas públicas al pago del alquiler, los beneficios económicos derivados de vivir en una vivienda social y las ayudas a los propietarios para satisfacer el importe de las hipotecas con medidas como la subsidiación de intereses o las ayudas directas al pago de las cuotas (European Commission, 2008). 


\section{Resultados}

\subsection{Aspectos generales de la burbuja residencial europea de los años 2000}

Los resultados corroboran la sincronización de los mercados europeos de vivienda. En la mayoría de los países, los precios subieron progresivamente hasta alcanzar su valor máximo o pico entre los años 2007 y 2008 para posteriormente descender. Solamente en Polonia y Hungría el valor máximo se situó antes o después de esos años. De los 28 países analizados, en 19 el precio de la vivienda cayó tras el valor máximo más de un $14 \%$, es decir, dos de cada tres habían sufrido una burbuja residencial según criterios del FMI. Cabe señalar que, a pesar de que en Portugal y Alemania la vivienda perdió más del 14\% de su valor real, estos no se incluyen entre los 19 países, porque sus procesos de devaluación no siguieron los patrones característicos de una burbuja: en lugar de experimentar fuertes fases de ascenso y caída, el precio real de la vivienda disminuyó lentamente desde el año 2000 hasta el 2008 en Alemania, y hasta 2013 en Portugal.

\subsection{Tipos de burbujas según el comportamiento de los fundamentales}

La clasificación de estos 19 países, tanto por el método jerárquico aglomerativo del vecino más lejano como por el no jerárquico de K-medias, arroja resultados coincidentes excepto en el caso de Italia, el cual analizaremos más adelante. Fundamentalmente pueden identificarse tres grupos (figura 1): uno que engloba la totalidad de países postcomunistas (grupo 1) (tabla 3); otro que aglutina la mayor parte de los mediterráneos, Islandia e Irlanda (grupo 2) (tabla 4), y un tercero formado solamente por Reino Unido, Holanda y Dinamarca (grupo 3) (tabla 4).

De los datos estadísticos de los países del grupo 1 cabe suponer que los principales motores de la expansión del mercado fueron el fuerte crecimiento económico y el acusado aumento de los ingresos disponibles. Durante el periodo 2000-2008, el incremento de los ingresos netos por habitante fue espectacular, de un $80 \%$ de media, es decir, un ritmo aproximado del $10 \%$ anual. Paradójicamente, esta mejora de los ingresos se produjo en un contexto de estancamiento demográfico o, en muchos casos, incluso de pérdida de población a causa de la emigración laboral dentro de la UE. Respecto a la oferta residencial, pese a la baja ratio de viviendas por habitante de estos países, la fase alcista no estuvo acompañada por un incremento significativo de la construcción residencial, por lo que cabe concluir que la oferta de vivienda de estos países, por lo general, fue muy inelástica. Otro aspecto que comparten todos ellos es el escaso grado de desarrollo de su política de vivienda, como así muestra el comportamiento entre los años 2000 y 2008 del gasto público en protección social en vivienda y la tasa de vivienda social. El parque social solo es destacable en Chequia y Polonia, debido a que en estos dos países, a diferencia del resto, el cambio de régimen no fue acompañado de una masiva privatización de la vivienda social construida en 
Figura 1. Dendograma del análisis jerárquico de conglomerados según el método del vecino más lejano, y resultados del análisis no jerárquico de conglomerados según el método de K-medias

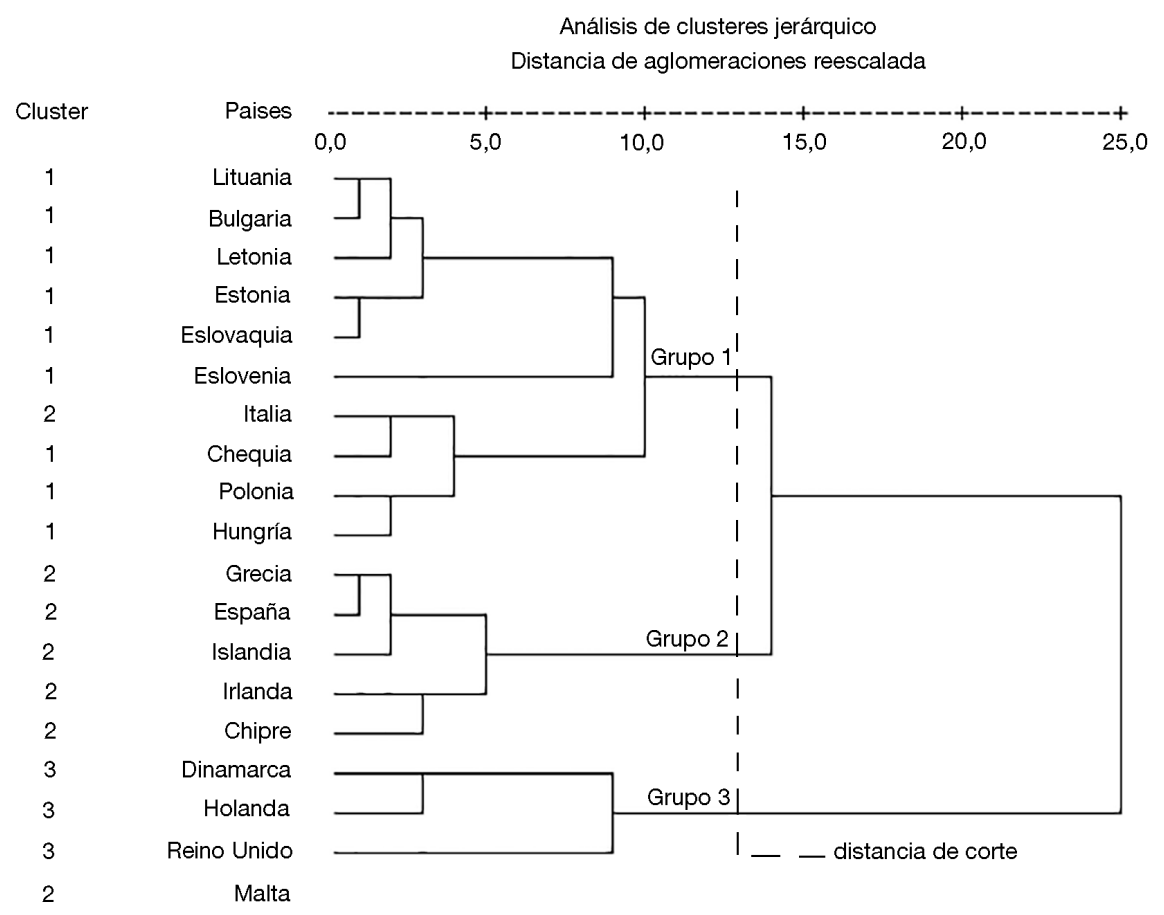

Fuente: elaboración propia.

el periodo comunista, sino que este ha sido un proceso lento, aún en desarrollo, impulsado por la transferencia del mismo a los gobiernos locales y las sucesivas reformas legislativas sobre su gestión patrimonial (Laino y Pittini, 2011). Por ello, los niveles de vivienda en propiedad, que ya eran elevados en la mayoría de estos países en 2000, siguieron incrementándose en detrimento del alquiler, ya sea del privado (Letonia, Lituania, Estonia, Eslovenia o Eslovaquia) o del social (Chequia y Polonia). Ello también ayuda a entender por qué la deuda hipotecaria creció intensamente durante el periodo alcista. Sin embargo, dado que era ínfima en el año 2000 a causa del débil desarrollo de sus sistemas bancario e hipotecario, cuando estalló la crisis los niveles de endeudamiento de los hogares continuaron siendo muy inferiores a los del resto de países europeos. Sin duda, el descenso del tipo de interés hipotecario real también contribuyó a la escalada del precio de la vivienda en los sistemas de vivienda postcomunistas, pero, comparativamente con el resto de países europeos, su valor medio anual a lo largo del periodo 2000-2008 no fue de los más bajos. 
Tabla 3. Datos estadísticos de la evolución del mercado residencial de los países del grupo 1 en el periodo 2000-2015

\begin{tabular}{|c|c|c|c|c|c|c|c|c|c|}
\hline Precio real de la vivienda & Letonia & Estonia & Lituania & Chequia & Bulgaria & Hungría & Eslovenia & Eslovaquia & Polonia \\
\hline Trimestre valor real máximo (pico) & 2007 3T & $20072 \mathrm{~T}$ & $20081 \mathrm{~T}$ & $20082 \mathrm{~T}$ & $20083 T$ & $20051 \mathrm{~T}$ & $20074 \mathrm{~T}$ & $20082 \mathrm{~T}$ & $20103 \mathrm{~T}$ \\
\hline $\begin{array}{l}\text { Valor real máximo }(\text { pico })(a) \\
\text { (año } 2000=\text { base } 100)\end{array}$ & 532,7 & 482,3 & 478,3 & 197,3 & 251,5 & 120,8 & 199,8 & 199,2 & 153,6 \\
\hline Trimestre valor real mínimo (postpico) & $20101 \mathrm{~T}$ & $20093 \mathrm{~T}$ & $20133 \mathrm{~T}$ & 2013 3Т & $20131 \mathrm{~T}$ & $20134 \mathrm{~T}$ & $20142 \mathrm{~T}$ & $20134 \mathrm{~T}$ & $20124 \mathrm{~T}$ \\
\hline $\begin{array}{l}\text { Valor real mínimo }(b) \text { (postpico) } \\
\text { (año } 2000=\text { base } 100)\end{array}$ & 205,6 & 210,0 & 222,3 & 103,8 & 139,2 & 73,6 & 109,6 & 139,9 & 117,4 \\
\hline Caída del valor real - $[1-(b) /(a)]$ & $-61,4 \%$ & $-56,5 \%$ & $-53,5 \%$ & $-47,4 \%$ & $-44,60 \%$ & $-39,1 \%$ & $-31,2 \%$ & $-29,8 \%$ & $-23,6 \%$ \\
\hline \multicolumn{10}{|l|}{ Aspectos macroeconómicos } \\
\hline $\begin{array}{l}\text { Valor PIB real per cápita máximo } \\
\text { (año } 2000=\text { base } 100 \text { ) }\end{array}$ & 205 & 177 & 199 & 144 & 173 & 134 & 143 & 165 & 148 \\
\hline $\begin{array}{l}\text { Ingresos netos disponibles máximos } \\
\text { por habitante en PPA (año } 2000=\text { base 100) }\end{array}$ & 223,2 & 193,3 & 220,6 & 148,6 & 193,8 & 155,0 & 145,7 & 188,0 & 152,5 \\
\hline \multicolumn{10}{|l|}{ Sistema financiero } \\
\hline Deuda hipotecaria 2000 (\% PIB) & 1,6 & 4,6 & 1,2 & 1,9 & 0,4 & 1,4 & 0,3 & 3,9 & 2,1 \\
\hline Deuda hipotecaria 2008 (\% PIB) & 29,5 & 37,6 & 18,5 & 9,4 & 10,4 & 20,9 & 9,0 & 13,0 & 14,2 \\
\hline $\begin{array}{l}\text { Tipo de interés hipotecario real } \\
\text { (media anual 2000-2008) }\end{array}$ & 1,5 & 1,1 & 2,9 & 2,1 & 3,7 & 6,0 & 3,5 & 1,1 & 5,1 \\
\hline \multicolumn{10}{|l|}{ Aspectos demográficos } \\
\hline Población año $2008(2000=100)$ & 92,0 & 95,5 & 91,5 & 100,6 & 91,8 & 98,3 & 101,1 & 99,6 & 99,6 \\
\hline \multicolumn{10}{|l|}{ Oferta y parque residencial } \\
\hline $\begin{array}{l}\text { Viviendas construidas } 2000-2008 \\
\text { (media anual por } 1.000 \text { habitantes) }\end{array}$ & 1,7 & 2,4 & 1,9 & 3,0 & 1,9 & 3,4 & 2,6 & 3,8 & 3,2 \\
\hline Tasa de vivienda en propiedad (2000) & 70,0 & 77,8 & 91,0 & 47,0 & 96,5 & 92,0 & 74,0 & 74,0 & 55,0 \\
\hline Tasa de vivienda en propiedad (2008) & 84,9 & 96,0 & 97,0 & 60,6 & 95,6 & 92,0 & 83,0 & 92,0 & 70,4 \\
\hline \multicolumn{10}{|l|}{ Política de vivienda } \\
\hline Tasa de vivienda social (año 2000) & 0,1 & 3,0 & 3,0 & 17,0 & 3,0 & 4,6 & 6,6 & 4,0 & 23,4 \\
\hline Tasa de vivienda social (año 2008) & 0,4 & 1,0 & 3,0 & 11,0 & 3,1 & 3,7 & 4,0 & 2,6 & 8,5 \\
\hline $\begin{array}{l}\text { Gasto público medio anual en protección } \\
\text { social en vivienda (\% PIB) }(2000-2008)\end{array}$ & 0,11 & 0,04 & 0,00 & 0,10 & 0,00 & 0,56 & 0,00 & 0,06 & 0,12 \\
\hline $\begin{array}{l}\text { Gasto público medio anual en ayudas al pago } \\
\text { del alquiler (\% PIB) (2000-2008) }\end{array}$ & 0,11 & 0,04 & 0,00 & 0,00 & 0,00 & 0,29 & 0,00 & 0,00 & 0,12 \\
\hline
\end{tabular}

Fuente: véase tablas 1 y 2.

Los países del grupo 2 muestran unos patrones sustancialmente diferentes. La evolución de los fundamentales en Irlanda, Grecia, Islandia, España, Chipre, Italia y Malta estuvo marcada, más allá del crecimiento económico y del aumento de los ingresos disponibles, por el fuerte incremento de la demanda por motivos demográficos y los extremadamente bajos tipos de interés. Entre 2000 y 2008, la población creció de forma importante en todos ellos por la inmigración, sobre todo en Irlanda (un 18\%), España (un 14\%), Islandia (un 13\%) y Chipre (un 12\%). Asimismo, a lo largo del mismo periodo, los tipos 
Tabla 4. Datos estadísticos de la evolución del mercado residencial de los países de los grupos 2 y 3 en el periodo 2000-2015

\begin{tabular}{|c|c|c|c|c|c|c|c|c|c|c|}
\hline \multirow[b]{2}{*}{ Precio real de la vivienda } & \multicolumn{7}{|c|}{ Países grupo 2} & \multicolumn{3}{|c|}{ Países grupo 3} \\
\hline & Irlanda & Grecia & España & Islandia & Chipre & Malta & Italia & Dinamarca & a Holanda & R. Unido \\
\hline Trimestre valor real máximo (pico) & $20071 \mathrm{~T}$ & $20073 \mathrm{~T}$ & $20073 T$ & $20074 \mathrm{~T}$ & $20082 T$ & $20071 \mathrm{~T}$ & $20081 \mathrm{~T}$ & $20071 \mathrm{~T}$ & $20084 \mathrm{~T}$ & $20074 \mathrm{~T}$ \\
\hline $\begin{array}{l}\text { Valor real máximo }(\text { pico })(a) \\
\text { (año } 2000=\text { base } 100)\end{array}$ & 174,1 & 158,7 & 208,2 & 191,2 & 247,4 & 155,4 & 149,0 & 169,6 & 131,1 & 188,4 \\
\hline Trimestre valor real mínimo (postpico) & $20131 \mathrm{~T}$ & $20154 \mathrm{~T}$ & $20134 \mathrm{~T}$ & $20103 \mathrm{~T}$ & $20152 \mathrm{~T}$ & 2012 2T & $20154 \mathrm{~T}$ & 2012 2T & $20132 \mathrm{~T}$ & $20092 \mathrm{~T}$ \\
\hline $\begin{array}{l}\text { Valor real mínimo }(b)(\text { postpico) } \\
\text { (año } 2000=\text { base } 100)\end{array}$ & 89,0 & 86,0 & 118,7 & 118,2 & 158,8 & 118,6 & 108,0 & 120,3 & 96,7 & 158,4 \\
\hline Caída del valor real - $[1-(\mathrm{b}) /(\mathrm{a})]$ & $-48,9 \%$ & $-45,9 \%$ & $-43,1 \%$ & $-38,2 \%$ & $-35,8 \%$ & $-23,7 \%$ & $-27,6 \%$ & $-29,1 \%$ & $-26,2 \%$ & $-15,9 \%$ \\
\hline \multicolumn{11}{|l|}{ Aspectos macroeconómicos } \\
\hline $\begin{array}{l}\text { Valor PIB real per cápita máximo } \\
\text { (año } 2000=\text { base } 100 \text { ) }\end{array}$ & 128 & 132 & 115 & 141 & 119 & 116 & 106 & 110 & 114 & 121 \\
\hline $\begin{array}{l}\text { Ingresos netos disponibles máximos por } \\
\text { habitante en PPA (año } 2000=\text { base 100) }\end{array}$ & 144,0 & 134,7 & 134,4 & 115,4 & 155,6 & n. d. & 114,9 & 129,1 & 128,6 & 130,8 \\
\hline \multicolumn{11}{|l|}{ Sistema financiero } \\
\hline Deuda hipotecaria 2000 (\% PIB) & 31,0 & 8,2 & 29,9 & 56,6 & 5,8 & 8,0 & 8,3 & 67,7 & 68,2 & 55,8 \\
\hline Deuda hipotecaria 2008 (\% PIB) & 79,6 & 32,1 & 60,4 & 65,4 & 45,3 & 36,2 & 17,3 & 106,9 & 92,6 & 80,4 \\
\hline $\begin{array}{l}\text { Tipo de interés hipotecario real } \\
\text { (media anual 2000-2008) }\end{array}$ & 0,9 & 0,9 & 0,9 & 0,3 & 3,4 & 0,8 & 2,3 & 2,5 & 2,5 & 3,2 \\
\hline \multicolumn{11}{|l|}{ Aspectos demográficos } \\
\hline Población año $2008(2000=100)$ & 118,0 & 102,6 & 114,0 & 113,0 & 112,4 & 107,4 & 103.0 & 102,7 & 103,4 & 104,7 \\
\hline \multicolumn{11}{|l|}{ Oferta y parque residencial } \\
\hline $\begin{array}{l}\text { Viviendas construidas } 2000-2008 \\
\text { (media anual por } 1.000 \text { habitantes) }\end{array}$ & 16,6 & 8,9 & 10,2 & 8,4 & 15,9 & 21,7 & 4,2 & 4,5 & 4,3 & 3,3 \\
\hline Tasa de vivienda en propiedad (2000) & 78,0 & 74,0 & 84,0 & 81,0 & 68,0 & 70,0 & 71,0 & 51,0 & 54,0 & 69,0 \\
\hline Tasa de vivienda en propiedad (2008) & 79,0 & 80,0 & 85,0 & 81,0 & 68,0 & 75,0 & 68,0 & 46,0 & 58,0 & 66,0 \\
\hline \multicolumn{11}{|l|}{ Política de vivienda } \\
\hline Tasa de vivienda social (año 2000) & 9,0 & 0,0 & 1,0 & 2,0 & 4,6 & 5,0 & 6,0 & 19,0 & 35,0 & 21,0 \\
\hline Tasa de vivienda social (año 2008) & 8,7 & 0,0 & 2,0 & 5,0 & 3,0 & 6,0 & 5,3 & 19,0 & 32,0 & 18,0 \\
\hline $\begin{array}{l}\text { Gasto público medio anual en protección } \\
\text { social en vivienda (\% PIB) (2000-2008) }\end{array}$ & 0,11 & 0,53 & 0,19 & 0,28 & 0,49 & 0,20 & 0,00 & 0,63 & 0,33 & 1,33 \\
\hline $\begin{array}{l}\text { Gasto público medio anual en ayudas al } \\
\text { pago del alquiler (\% PIB) (2000-2008) }\end{array}$ & 0,11 & 0,23 & 0,00 & 0,18 & 0,12 & 0,00 & 0,00 & 0,63 & 0,31 & 1,33 \\
\hline
\end{tabular}

Fuente: véase tablas 1 y 2 .

de interés reales se situaron, en valor promedio, por debajo del $1 \%$ anual en todos los países de este grupo excepto en Chipre. Lógicamente, la evolución de estas dos variables sumada a la existencia de un potente sector de la construcción y a la disponibilidad de suelo donde promover propulsó la obra nueva residencial. Entre los años 2000 y 2008 el ritmo de construcción de nuevas viviendas fue extraordinario: siempre por encima de las 8 viviendas anuales por cada 1.000 habitantes, e incluso superior a las 20 viviendas anuales en Malta. Este volumen ingente de nuevas viviendas se incorporó en su mayor 
Tabla 5. Datos estadísticos de la evolución del mercado residencial de los países europeos que no sufrieron ninguna burbuja en el periodo 2000-2015

\begin{tabular}{|c|c|c|c|c|c|c|c|c|c|}
\hline Precio real de la vivienda & Portugal & Alemania & Noruega & Finlandia & Francia & Suecia & Luxemb. & Bélgica & Austria \\
\hline Trimestre valor real máximo (pico) & $20004 \mathrm{~T}$ & $20001 \mathrm{~T}$ & 2007 3T & 2007 3Т & $20074 \mathrm{~T}$ & $20074 \mathrm{~T}$ & $20073 \mathrm{~T}$ & $20084 \mathrm{~T}$ & $20134 \mathrm{~T}$ \\
\hline $\begin{array}{l}\text { Valor real máximo }(\text { pico) }(\mathrm{a}) \\
\text { (año } 2000=\text { base } 100)\end{array}$ & 103,4 & 100,0 & 161,2 & 133,5 & 187,6 & 176,5 & 195,5 & 156,3 & 120,1 \\
\hline Trimestre valor real mínimo (postpico) & $20132 \mathrm{~T}$ & $20081 \mathrm{~T}$ & $20084 \mathrm{~T}$ & $20091 \mathrm{~T}$ & $20093 \mathrm{~T}$ & $20091 \mathrm{~T}$ & $20093 \mathrm{~T}$ & $20092 \mathrm{~T}$ & - \\
\hline $\begin{array}{l}\text { Valor real mínimo (b) (postpico) } \\
\text { (año } 2000=\text { base } 100)\end{array}$ & 68,9 & 83,5 & 142,8 & 121,7 & 169,5 & 165,6 & 186,6 & 154,2 & - \\
\hline Caída del valor real - [1 - (b)/(a)] & $-33,1 \%$ & $-16,5 \%$ & $-11,4 \%$ & $-9,8 \%$ & $-9,7 \%$ & $-6,2 \%$ & $-4,6 \%$ & $-1,4 \%$ & $0,0 \%$ \\
\hline \multicolumn{10}{|l|}{ Aspectos macroeconómicos } \\
\hline $\begin{array}{l}\text { Valor PIB real per cápita máximo } \\
\text { (año } 2000=\text { base } 100 \text { ) }\end{array}$ & 105 & 113 & 112 & 125 & 109 & 123 & 122 & 112 & 116 \\
\hline $\begin{array}{l}\text { Ingresos netos disponibles } \\
\text { máximos por habitante en PPA } \\
\text { (año } 2000=\text { base } 100 \text { ) }\end{array}$ & 122,3 & 133,3 & 155,6 & 134,1 & 120,6 & 133,2 & 134,4 & 117,4 & 125,6 \\
\hline \multicolumn{10}{|l|}{ Sistema financiero } \\
\hline Deuda hipotecaria 2000 (\% PIB) & 41,5 & 53,2 & 39,1 & 20,4 & 21,2 & 44,6 & 25,0 & 27,7 & 16,4 \\
\hline Deuda hipotecaria 2008 (\% PIB) & 58,8 & 46,3 & 59,9 & 34,9 & 35,1 & 65,7 & 42,3 & 39,7 & 24,7 \\
\hline $\begin{array}{l}\text { Tipo de interés hipotecario real } \\
\text { (media anual 2000-2008) }\end{array}$ & 1,6 & 3,3 & 4,1 & 2,6 & 2,5 & 2,2 & 1,2 & 2,9 & 2,8 \\
\hline \multicolumn{10}{|l|}{ Aspectos demográficos } \\
\hline Población año $2008(2000=100)$ & 102,9 & 100,1 & 105,8 & 102,5 & 105,7 & 103,6 & 111,6 & 104,2 & 103,8 \\
\hline \multicolumn{10}{|l|}{ Oferta y parque residencial } \\
\hline $\begin{array}{l}\text { Viviendas construidas } 2000-2008 \\
\text { (media anual por } 1.000 \text { habitantes) }\end{array}$ & 8,4 & 3,3 & 4,7 & 6,0 & 6,0 & 2,6 & 5,5 & 4,6 & 5,0 \\
\hline Tasa de vivienda en propiedad (2000) & 75,0 & 41,0 & 62,5 & 64,0 & 55,0 & 50,9 & 70,0 & 68,0 & 52,0 \\
\hline Tasa de vivienda en propiedad (2008) & 75,0 & 42,0 & 62,0 & 66,0 & 57,8 & 56,0 & 75,0 & 68,0 & 56,0 \\
\hline \multicolumn{10}{|l|}{ Política de vivienda } \\
\hline Tasa de vivienda social (año 2000) & 3,3 & 6,5 & 4,0 & 16,0 & 16,0 & 19,0 & 1,9 & 7,0 & 23,0 \\
\hline Tasa de vivienda social (año 2008) & 3,3 & 4,6 & 5,0 & 16,0 & 17,0 & 18,0 & 2,0 & 7,0 & 23,0 \\
\hline $\begin{array}{l}\text { Gasto público medio anual en } \\
\text { protección social en vivienda } \\
(\% \text { PIB) }(2000-2008)\end{array}$ & 0,00 & 0,45 & 0,14 & 0,30 & 0,79 & 0,51 & 0,19 & 0,09 & 0,11 \\
\hline $\begin{array}{l}\text { Gasto público medio anual } \\
\text { en ayudas al pago del alquiler } \\
\text { (\% PIB) }(2000-2008)\end{array}$ & 0,00 & 0,45 & 0,08 & 0,29 & 0,71 & 0,51 & 0,10 & 0,08 & 0,11 \\
\hline
\end{tabular}

Fuente: véase tablas 1 y 2.

parte al mercado de compraventa, pues la propiedad es también la forma de tenencia mayoritaria en estos países, lo que desbocó la deuda hipotecaria de los hogares. En apenas 8 años de expansión, creció en cerca de 50 puntos del PIB en Irlanda, 40 en Chipre y más de 30 en España. La política de vivienda también constituye un elemento clave para entender el funcionamiento de los 
sistemas residenciales de este grupo. El gasto público en este campo suele ser muy bajo, principalmente orientado a promover la vivienda en propiedad, y el parque de vivienda social, minúsculo (Irlanda, con un $9 \%$ de las viviendas principales de alquiler social, es la única excepción). Todo ello implica un elevadísimo grado de mercantilización del bien vivienda. La atención de las necesidades residenciales se lleva a cabo mayoritariamente en el mercado libre, por lo que aquellos hogares sin capacidad económica quedan sistemáticamente excluidos del mismo. En otras palabras, la dimensión económica del bien vivienda predomina claramente sobre la social.

En esta clasificación, Italia constituye un caso particular. Es el único país que, según el método empleado, se integra en el grupo 1 (si usamos el jerárquico del vecino más lejano) o en el grupo 2 (si usamos el no jerárquico de K-medias) (figura 1). Ello se debe a que en muchas de las variables consideradas ocupa una posición intermedia entre los países del grupo 1 y los del grupo 2, como, por ejemplo, en cuestión de crecimiento demográfico, ritmo de construcción de nuevas viviendas o evolución de los ingresos disponibles por habitante. En esta situación, hemos considerado que lo más oportuno era clasificar Italia dentro del grupo 2, porque comparte más características históricas, económicas y sociopolíticas con el resto de países mediterráneos del grupo 2 que con los postcomunistas del grupo 1 .

Dinamarca, Holanda y el Reino Unido constituyen el grupo 3. En estos, es probable que influyeran en la evolución alcista del precio: la mejora de los ingresos netos disponibles que se produjo entre 2000 y 2008, así como los bajos niveles de construcción de nuevas viviendas (las tasas medias anuales de estos países oscilaron entre las 3 y 4 viviendas nuevas por cada 1.000 habitantes). Por el contrario, cabe pensar que el descenso de los precios fue más moderado, menor que en los grupos anteriores, a causa del débil crecimiento demográfico del periodo 2000-2008 (inferior al 5\% en los tres países), del mantenimiento de unas tasas de vivienda en propiedad significativamente inferiores a los del grupo 1 y 2 (siempre por debajo del $70 \%$ ) y de su elevado grado de desarrollo de la política de vivienda, tanto en términos de gasto público como de porcentaje de vivienda social. Otro rasgo distintivo es la deuda hipotecaria (tabla 4). En 2008, los hogares de estos tres países eran los que sufrían los mayores niveles de endeudamiento hipotecario de toda Europa.

Por su parte, es posible observar ciertas características comunes entre los países cuyos mercados residenciales no sufrieron ninguna burbuja (tabla 5). En la mayoría de ellos, el incremento de la deuda hipotecaria que tuvo lugar entre 2000 y 2008 fue, como máximo, de 20 puntos del PIB, no llegando a sobrepasar el umbral del 65\% del PIB; el crecimiento demográfico fue leve (solo en Luxemburgo llegó al 11,6\% entre 2000 y 2008); los ritmos de construcción de vivienda nueva, como máximo, se situaron en las seis viviendas anuales por cada mil habitantes (excepto en Portugal, donde se construyeron cada año de media 8,4 viviendas por cada mil habitantes), y las tasas de vivienda en propiedad siempre fueron inferiores al $80 \%$ del parque principal y, en muchos casos, aún menores, entre el 50\% y el 70\%. Asimismo, el grado de 
desarrollo de la política de vivienda de la mayor parte de ellos debe calificarse de elevado, particularmente en Austria, Suecia, Francia, Finlandia y Alemania. Solo Portugal y Luxemburgo muestran unos pobres indicadores en este campo, tanto en cuestión de alquiler social como en gasto público en ayudas al pago de la vivienda.

\section{Conclusiones y discusión}

Desde una perspectiva histórica basada en los datos disponibles de los últimos 50 años, la burbuja residencial europea de los años 2000 fue un fenómeno excepcional, tanto por el gran número de sistemas residenciales afectados como por la simultaneidad, magnitud y duración de la fase de caída. Mientras que entre los años 1973 y 2002 se produjeron en todo el mundo solo 20 burbujas residenciales en 14 países, con una caída media del 30\% del valor y una duración de 4 años (Helbling y Terrones, 2003), en el periodo 2000-2015, y solamente en Europa, hemos identificado 19 burbujas correspondientes a otros tantos países, cuya fase deflacionaria duró, de media, algo más de 5 años y causó una pérdida promedio del $38 \%$ de precio real de la vivienda.

Esta burbuja residencial europea estuvo asociada, por lo general, con fuertes aumentos de la deuda hipotecaria, elevadas tasas de vivienda en propiedad y una escasa intervención pública, centrada prioritariamente en el fomento de la vivienda en propiedad en detrimento de la vivienda social y del sistema de ayudas al pago del alquiler. Tales conclusiones son consistentes con un creciente corpus teórico y empírico que defiende que esta volatilidad de los mercados residenciales europeos fue fruto de un proceso político-económico basado en la mercantilización de la economía y la sociedad, la desregulación de los sistemas financieros e hipotecarios y el progresivo desmantelamiento del Estado de bienestar en pro de la implementación de la ortodoxia económica neoliberal (Stephens, 2007; Bone y O’Reilly, 2010; Rolnik, 2013; Aalbers, 2015).

No obstante, a pesar de estas características comunes, los países afectados por la burbuja presentan un significativo grado de heterogeneidad en cuanto a la evolución durante la fase alcista del resto de factores determinantes en la formación de los precios residenciales, lo que sugiere la existencia de diferentes modelos de burbuja en el contexto europeo. Tal hipótesis se verifica en el análisis de clústeres basado en el comportamiento de 13 variables representativas de los factores demográficos, financieros, macroeconómicos, de política de vivienda y de la oferta residencial de estos países. Dicho análisis revela la existencia de tres tipos de burbujas residenciales en el periodo 2000-2015.

Un tipo de burbuja sería el que ha afectado a todos los países postcomunistas. Esta se caracterizaría por la combinación de una oferta residencial inelástica y una demanda creciente, no por razones demográficas, sino por la mejora de las condiciones económico-financieras. Tales conclusiones son coherentes con la literatura existente. Numerosos autores subrayan la existencia de una serie de factores específicos en estos países, como, por ejemplo, el gran impacto de las remesas de dinero de los trabajadores emigrados en los ingresos disponibles 
de los hogares, el reciente desarrollo de sus sistemas hipotecarios (Shelburne y Palacin, 2006; Égert y Mihaljek, 2007a, 2007b; Stepanyan et al., 2010; Huynh-Olesen et al., 2013) o el hecho de que la vivienda estuviera infravalorada antes del inicio del periodo expansivo (Égert y Mihaljek, 2007a, 2007b).

El segundo tipo de burbuja englobaría a Irlanda, Grecia, Islandia, España, Chipre y Malta. En estos países, la evolución de la práctica totalidad de los factores examinados contribuyó, en mayor o menor medida, a su formación: formidable aumento de la demanda, tanto por motivos demográficos como económicos a causa del crecimiento de los ingresos, drástica caída de los tipos hipotecarios de interés, sobreoferta de productos financieros (lo que permitió que los mercados absorbieran la enorme producción de nueva vivienda) y una débil política de vivienda centrada en promover la propiedad. La mayoría de los estudios sobre la evolución de los mercados de vivienda de estos países coincide con este diagnóstico. Según el FMI, el precio de la vivienda subió con fuerza en España por una combinación de factores propicios: fuerte aumento del empleo, intenso crecimiento del número de hogares (debido a la emancipación de las generaciones del baby boom y las elevadas tasas de inmigración), incremento de los ingresos, extraordinaria liquidez del sistema financiero y tipos de interés reales muy bajos (IMF, 2009). De un modo parecido, Malzubris (2008) sostiene que, en Irlanda, la mayor parte del incremento del precio de la vivienda desde 1992 hasta 2006 se debe a la mejora de los ingresos disponibles, la caída de los tipos de interés, el incremento demográfico y el tratamiento fiscal favorable para la propiedad. Por consiguiente, respecto al marco teórico existente, en estos países, por un lado, se confirma el cumplimiento del modelo de oferta y demanda agregada, es decir, que el incremento de la demanda por motivos demográficos crea tensiones inflacionistas, $\mathrm{y}$, por otro lado, se corroboran los resultados de Glaeser et al. (2008) en lo relativo a la posibilidad de que se produzcan burbujas especulativas incluso en mercados residenciales con una oferta muy elástica.

El tercer tipo de burbuja, la cual afectaría a Dinamarca, Holanda y Reino Unido, tiene como principal característica el elevado endeudamiento hipotecario de los hogares, superior al de cualquier otro país europeo. Por ello, sospechamos que la escalada del precio de la vivienda estuvo impulsada esencialmente por una sobreoferta hipotecaria. Este planteamiento se alinea con los postulados de Levitin y Wachter (2012) sobre el mercado estadounidense. Estos autores admiten la existencia de múltiples causas en la formación de la burbuja residencial estadounidense, pero insisten en que el principal componente fue una burbuja hipotecaria generada por errores sistémicos en el cálculo del riesgo asociado. Numerosas investigaciones sobre la burbuja en Dinamarca, Holanda y Reino Unido respaldan esta tesis, al destacar la importancia de las nuevas soluciones hipotecarias en la expansión del crédito, por ejemplo, mediante los préstamos diferidos o de amortización diferida en los que una parte del principal se paga íntegramente al final del plazo de amortización (Bardhan, et al., 2011; Dam et al., 2011; IMF, 2014). Otra de las explicaciones más recurrentes es la escasa elasticidad de la oferta residencial de estos sistemas 
(Barker, 2006; Hoeller y Rae, 2007; Vermeulen y Rouwendal, 2007; Cunha et al., 2008; Fortune y Moohan, 2008; Muellbauer y Murphy, 2008; Niemietz, 2012; Chandler y Disney, 2014; IMF, 2014). Ciertamente, la producción de vivienda en Dinamarca, Holanda y Reino Unido durante el periodo 20002008 fue moderada, entre 3,3 y 4,5 viviendas anuales por cada 1.000 habitantes, pero aparentemente congruente con el leve crecimiento demográfico que experimentaron, por lo que resulta difícil considerar la inelasticidad de la oferta como un elemento clave en la evolución del precio. En cualquier caso, este extremo requeriría un estudio más detallado.

Los resultados obtenidos tienen importantes implicaciones. Desde una perspectiva práctica, aconsejan la adopción de determinadas medidas para evitar los comportamientos especulativos. La intervención pública debería centrarse en la promoción de vivienda social y en el desarrollo de un sistema de ayudas al pago del alquiler, tanto de forma directa mediante la política de vivienda como de forma indirecta mediante políticas relacionadas, como, por ejemplo, la fiscal, la monetaria o la regulatoria del sistema hipotecario. Además, de forma complementaria, también debería incentivarse el alquiler privado con marcos legislativos que ofrezcan estabilidad al inquilino, políticas de movilización de la vivienda vacía, desgravaciones fiscales, etc. Con todo ello, cabe prever el restablecimiento de un mayor equilibrio entre regímenes de tenencia, así como entre las dimensiones económica y social de la vivienda.

Desde una perspectiva teórica, resulta evidente que, ante la complejidad de los sistemas residenciales, el comportamiento de los precios debe abordarse desde un planteamiento multidimensional que englobe, como mínimo, los principales factores que inciden en su formación y que tenga en consideración el contexto político y económico de cada país. En caso contrario, existe el riesgo de obtener conclusiones sesgadas o incluso erróneas. Por ejemplo, los mercados residenciales de los países postcomunistas (grupo 1) tuvieron una dinámica propia a lo largo del periodo 2000-2015 que no puede entenderse sin una visión histórico-política más amplia.

Llegados a este punto, resulta necesario remarcar las principales limitaciones de este estudio para una correcta interpretación de los resultados. En primer lugar, hay que tener presente que la metodología empleada no permite establecer relaciones de causalidad entre variables, aunque estas encuentren soporte en multitud de trabajos teóricos y empíricos. En segundo lugar, las variables empleadas son suficientes para el propósito de esta investigación, pero no para examinar en profundidad cada una de las tipologías de burbuja, y mucho menos para analizar pormenorizadamente ningún país. En estos casos, sería imprescindible incorporar información más detallada de todos los factores considerados. Por ejemplo, en el plano demográfico deberían contemplarse aspectos como: las migraciones internas y externas, los ritmos de formación y destrucción de hogares o los procesos de emancipación. De igual modo, las variables financieras podrían ampliarse con la duración media del crédito hipotecario, la relación entre préstamo hipotecario y valor de inmueble, así como entre cuota hipotecaria e ingresos del hogar. 
Por último, cabe destacar que, tanto para corregir las limitaciones antes mencionadas como para ampliar el conocimiento sobre el comportamiento de los mercados residenciales, los resultados obtenidos pueden servir de base para futuras investigaciones. Estas, entre otros, pueden tener como objetivo perfeccionar los modelos econométricos de detección de burbujas residenciales, avanzar en el conocimiento de cada uno de los tres tipos de burbuja identificados mediante el uso de nuevas variables y otras metodologías estadísticas o definir un sistema de indicadores compuestos que permitan valorar objetivamente el riesgo de dinámicas especulativas.

\section{Referencias bibliográficas}

AalbERS, Manuel B. (2015). «The Great Moderation, the Great Excess and the global housing crisis». International Journal of Housing Policy, 15 (1), 43-60. <http://dx.doi.org/10.1080/14616718.2014.997431>

AGNELLO, Luca y SCHUKNECHT, Ludger (2011). «Booms and busts in housing markets: Determinants and implications». Journal of Housing Economics, 20 (3), 171-190. $<$ http://dx.doi.org/10.1016/j.jhe.2011.04.001>

Ahearne, Alan G.; Ammer, John; Doyle, Brian M.; Kole, Linda S. y Martin, Robert F. (2005). House prices and monetary policy: A cross-country study. International Finance Discussion Papers 841. Washington: Board of Governors of the Federal Reserve System.

AHRend, Rudiger; COURnÈDe, Boris y PRICE, Robert W. R. (2008). Monetary Policy, Market Excesses and Financial Turmoil. OECD Economics Department Working Papers 597. París: OECD Publishing. $<$ http://dx.doi.org/10.1787/244200148201>

AlgierI, Bernardina (2013). «House Price Determinants: Fundamentals and Underlying Factors». Comparative Economic Studies, 55 (2), 315-341. $<$ http://dx.doi.org/10.1057/ces.2013.3>

ANDERSEN, Hans Skifter (2012). Housing policy in the Nordic countries and its implication for the housing of immigrants. Hørsholm: SBI Forlag y Danish Building Research Institute, Aalborg University.

ANDRÉ, Christophe (2010). A Bird's Eye View of OECD Housing Markets. OECD Economics Department Working Papers 746. París: OECD Publishing. $<$ http://dx.doi.org/10.1787/5kmlh5qvz1s4-en>

ANDREWS, Dan y CALDERA, Aida (2011). Drivers of homeownership rates in selected OECD countries. OECD Economics Department Working Papers 849. París: OECD Publishing. $<$ http://dx.doi.org/10.1787/5kgg9mcwc7jf-en>

ANDREWS, Dan; CALDERA, Aida y JOHANSSON, Åsa (2011). Housing markets and structural policies in OECD countries. OECD Economics Department Working Papers 836. París: OECD Publishing. $<$ http://dx.doi.org/10.1787/5kgk8t2k9vf3-en>

ANTONIUCCI, Valentina y MARelLA, Giuliano (2016). «Small town resilience: Housing market crisis and urban density in Italy». Land Use Policy, 59, 580-588. $<$ http://dx.doi.org/10.1016/j.landusepol.2016.10.004>

ARSHANAPALLI, Bala y NELSON, William (2008). «A cointegration test to verify the housing bubble». The International Journal of Business and Finance Research, 2 (2), 35-43. 
Azevedo, Alda Botelho; López-ColÁs, Julián y Módenes, Juan Antonio (2016). «Home ownership in Southern European countries: Similarities and differences». Portuguese Journal of Social Science, 15 (2), 275-298. $<$ https://doi.org/10.1386/pjss.15.2.275_1>

Backé, Peter; Gnan, Ernest y Hartmann, Philipp (eds.) (2010). Contagion and Spillovers: New Insights from the Crisis. The European Money and Finance Forum, SUERF Studies 5. Viena: SUERF.

Bardhan, Ashok; Edelstein, Robert y Kroll, Cynthia A. (2011). A Comparative Context for US Housing Policy: Housing Markets and the Financial Crisis in Europe, Asia, and Beyond. Washington: Bipartisan Policy Center.

BARKER, Kate (2006). Barker Review of Land Use Planning: Final Report-Recommendations. Londres: The Stationery Office.

Black, Angela; Fraser, Patricia y Hoesli, Martin (2006). «House prices, fundamentals and bubbles». Journal of Business Finance \& Accounting, 33 (9-10), 1535-1555. <http://dx.doi.org/10.1111/j.1468-5957.2006.00638.x>

Bone, John y O'ReILly, Karen (2010). «No place called home: The causes and social consequences of the UK housing bubble». The British Journal of Sociology, 61 (2), 231-255. <http://dx.doi.org/10.1111/j.1468-4446.2010.01311.x>

Brunnermeier, Markus K. y Oehmke, Martin (2013). «Bubbles, Financial Crisis and Systemic Risk». En: COnSTANTINIDES, George M.; Harris, Milton y STUlZ Rene M. (eds.). Handbook of the Economics of Finance, vol. 2. Amsterdam: Elsevier 1221-1288. <http://dx.doi.org/10.1016/B978-0-44-459406-8.00018-4>

BrunnermeIER, Markus K. y Julliard, Christian (2008). «Money Illusion and Housing Frenzies». Review of Financial Studies, 21 (1), 135-180. <http://dx.doi.org/10.1093/rfs/hhm043>

BRYANT, Sarah K. y KoHn, Jonathan W. (2013). «A Housing Bubble Debate Resolved». Journal of Applied Finance and Banking, 3 (4), 55-72.

CALDERA, Aida y JOHANSSON, Åsa (2013). «The price responsiveness of housing supply in OECD countries». Journal of Housing Economics, 22 (3), 231-249. <http://dx.doi.org/10.1016/j.jhe.2013.05.002>

CAMPBELL, John Y. y SHILlER, Robert (1987). «Cointegration and tests of present value models». Journal of Political Economy, 95 (5), 1062-1088. $<$ http://dx.doi.org/10.1086/261502>

Capozza, Dennis R.; HendershotT, Patric H.; Mack, Charlotte y Mayer, Christopher J. (2002). Determinants of Real House Price Dynamics. NBER Working Paper 9262. Cambridge: National Bureau of Economic Research.

CASE, Karl E. y SHILler, Robert (2003). «Is There a Bubble in the Housing Market?». Brookings Papers on Economic Activity, 2, 299-362. <http://dx.doi.org/10.1353/eca.2004.0004>

Catte, Pietro; Girouard, Nathalie; Price, Robert y André, Christophe (2004). Housing Markets, Wealth and the Business Cycle. OECD Economics Department Working Papers 394. París: OECD Publishing. <http://dx.doi.org/10.1787/534328100627>

Chandler, Daniel y Disney, Richard (2014). «Housing market trends and recent policies». En: Emmerson, Carl; Johnson, Paul y Miller, Helen (eds.). The IFS Green Budget 2014. Londres: Institute for Fiscal Studies, 90-125.

<http://dx.doi.org/10.1920/re.ifs.2014.0091> 
Ciarlone, Alessio (2015). «House price cycles in emerging economies». Studies in Economics and Finance, 32 (1), 17-52. <http://dx.doi.org/10.1108/SEF-11-2013-0170>

CLARK, William A. V. (2013). "The aftermath of the general financial crisis for the ownership society: What happened to low-income homeowners in the US?». International Journal of Housing Policy, 13 (3), 227-246. <http://dx.doi.org/10.1080/14616718.2013.796811>

CRAINE, Roger (1993). «Rational bubbles: A test». Journal of Economic Dynamics and Control, 17 (5-6), 829-846. <http://dx.doi.org/10.1016/0165-1889(93)90017-M>

Crook, Tony y Kemp, Peter A. (eds.) (2014). Private Rental Housing: Comparative Perspectives. Cheltenham: Edward Elgar Publishing.

Crowe, Christopher; Dell'Ariccia, Giovanni; Igan, Deniz y Rabanal Pau (2013). «How to deal with real estate booms: Lessons from country experiences». Journal of Financial Stability, 9 (3), 300-319. <http://dx.doi.org/10.1016/j.jfs.2013.05.003>

CunHA, Ricardo M.; LAmbreCHT, Bart M. y PAwlina, Grzegorz (2008). «The Dutch housing market: Trends, risks, and outlook». Journal of Financial Transformation, $22,18-22$.

CunNingham, Rose y Kolet, Ilan (2011). «Housing market cycles and duration dependence in the United States and Canada». Applied Economics, 43, 569-586. <http://dx.doi.org/10.1080/00036840802584927>

Cvijanovic, Dragana; Favilukis, Jack y PolK, Christopher (2010). New in Town: Demographics, Immigration, and the Price of Real Estate. Londres: London School of Economics.

CZISCHKe, Darinka y PITTINI, Alice (2007). Housing Europe 2007. Review of social, co-operative and public housing in the $27 \mathrm{EU}$ member states. Bruselas: European Social Housing Observatory, CECODHAS.

Dam, Niels Arne; Hvolbøl, Tina Saaby; Pedersen, Erik Haller; Sørensen, Peter Birch y THAMSBORG, Susanne Hougaard (2011). «The Housing Bubble that Burst: Can House Prices be Explained? And Can Their Fluctuations be Dampened?». En: Sørensen, Peter Birch (ed.). Monetary Review 1st Quarter. Copenhague: Danmarks Nationalbank, 47-70.

DavidofF, Thomas (2013). «Supply Elasticity and the Housing Cycle of the 2000s». Real Estate Economics, 41 (4), 793-813. <http://dx.doi.org/10.1111/1540-6229.12019>

Del Negro, Marco y OtroK, Christopher (2007). «99 Luftballons: Monetary policy and the house price boom across U.S. states». Journal of Monetary Economics, 54, 1962-1985. <http://dx.doi.org/10.1016/j.jmoneco.2006.11.003>

Diba, Behzad y Grossman, Herschel (1988). «Explosive rational bubbles in stock prices?». American Economic Review, 78 (3), 520-530.

DieCI, Roberto y WeSTERHOFF, Frank (2016). «Heterogeneous expectations, boombust housing cycles, and supply conditions: A nonlinear dynamics approach». Journal of Economic Dynamics and Control, 71, 21-44. <http://dx.doi.org/10.1016/j.jedc.2016.07.011>

Dol, Kees y HafFner, Marietta (eds.) (2010). Housing statistics in the European Union 2010. La Haya: Ministry of the Interior and Kingdom Relations y OTB Research Institute for the Built Environment. Delft University of Technology. 
DOMANSKI, Henryk y NorRIs, Michelle (2009). «Housing Conditions, States, Markets and Households: A Pan-European Analysis». Journal of Comparative Policy Analysis: Research and Practice, 11 (3), 385-407. <http://dx.doi.org/10.1080/13876980903158027>

DuCA, John V.; Muellbauer, John y MurPhy, Anthony (2010). «Housing markets and the financial crisis of 2007-2009: Lessons for the future». Journal of Financial Stability, 6 (4), 203-217. <http://dx.doi.org/10.1016/j.jfs.2010.05.002>

Égert, Balázs y MihaljeK, Dubravko (2007a). «Determinants of House Price Dynamics in Central and Eastern Europe». En: MoosleChner, Peter y RitzBERGER-GRÜNWALD, Doris (eds.). Focus on European Economic Integration 1/07. Viena: Austrian National Bank, 52-76.

- (2007b). «Determinants of House Prices in Central and Eastern Europe». Comparative Economic Studies, 49 (3), 367-388. $<$ http://dx.doi.org/10.1057/palgrave.ces.8100221>

EMF (2009). Hypostat 2008: A Review of Europes Mortgage and Housing Markets. Bruselas: European Mortgage Federation.

- (2010). Hypostat 2009: A Review of Europes Mortgage and Housing Markets. Bruselas: European Mortgage Federation.

- (2012). Hypostat 2011. A Review of Europes Mortgage and Housing Markets. Bruselas: European Mortgage Federation.

EUROPEAN COMMISSION (2008). ESSPROS Manual: The European system of integrated social protection statistics (ESSPROS). Luxemburgo: Office for Official Publications of the European Communities.

FEDERCASA (eds.) (2006). Housing Statistics in the European Union 2005/2006. Roma: Italian Housing Federation. Ministry of Infrastructure of the Italian Republic.

ForTunE, Charlotte Catherine y MoOHAN, James Anthony John (2008). «International variations in new housing supply». International Journal of Housing Markets and Analysis, 1 (4), 379-392. <http://dx.doi.org/10.1108/17538270810908669>

Froot, Kenneth A. y OBSTFELD, Maurice (1991). «Intrinsic Bubbles: The Case of Stock Prices». The American Economic Review, 81 (5), 1189-1214.

Gattini, Luca y Hiebert, Paul (2010). Forecasting and Assessing Euro Area House Prices Through the Lens of Key Fundamentals. ECB Working Paper 1249. Frankfurt: European Central Bank.

Gerdesmeier, Dieter; Lenarcic, Andreja y Roffia, Barbara (2012). An Alternative Method for Identifying Booms and Busts in the Euro Area Housing Market. ECB Working Paper 1493. Frankfurt: European Central Bank.

GlaESER, Edward y GYOURKO, Joseph (2006). Housing Dynamics. NBER Working Paper 12787. Cambridge, MA: National Bureau of Economic Research.

Glaeser, Edward; GyourKo, Joseph y SaIZ, Albert (2008). «Housing Supply and Housing Bubbles». Journal of Urban Economics, 64 (2), 198-217. <http://dx.doi.org/10.1016/j.jue.2008.07.007>

Grimes, Arthur y AitKen, Andrew (2010). «Housing supply, land costs and price adjustment». Real Estate Economics, 38 (2), 325-353. <http://dx.doi.org/10.1111/j.1540-6229.2010.00269.x>

Grossman, Gene y Yanagawa Noriyuki (1993). «Asset bubbles and endogenous growth". Journal of Monetary Economics, 31 (1), 3-19. <http://dx.doi.org/10.1016/0304-3932(93)90014-7> 
Haynes, Kingsley E.; KulKarni, Rajendra; Stough, Roger R. y ScHINTLER, Laurie (2010). Exploratory Analyses of the US Housing Bubble with Kolmogorov Entropy and Principal Component Analysis (PCA). Research Paper 2010-20. Fairfax: School of Public Policy, George Mason University. <http://dx.doi.org/10.2139/ssrn.1590309>

Hegedus, József; Teller, Nóra y Lux, Martin (2013). Social Housing in Transition Countries. Abingdon: Routledge.

Helbling, Thomas y Terrones, Marco (2003). "When bubbles burst». En: IMF (2003). World Economic Outlook April 2003 Growth and Institutions. Washington: International Monetary Fund, 61-94.

Hessel, Jeroen y PEETERS, Jolanda (2011). Housing bubbles, the leverage cycle and the role of central banking. DNB Occasional Studies, 9 (5). Amsterdam: De Nederlandsche Bank.

Hilbers, Paul; Hoffmaister, Alexander W.; BAnerji, Angana y Sui, Haiyan (2008). House Price Developments in Europe: A Comparison. IMF Working Paper 08/211. Washington: International Monetary Fund. <http://dx.doi.org/10.5089/9781451870695.001>

Himmelberg, Charles; Mayer, Christoph y SinaI, Todd (2005). «Assessing High House Prices: Bubbles, Fundamentals, and Misperceptions». Journal of Economic Perspectives, 19 (4), 67-92. <http://dx.doi.org/10.1257/089533005775196769>

Hoeller, Peter y RAE, David (2007). Housing Markets and Adjustments in Monetary Union. OECD Economics Department Working Papers 550. París: OECD Publishing. $<$ http://dx.doi.org/10.1787/208627725571>

Holly, Sean y JONES, Natasha (1997). «House Prices since 1940s: Cointegration, Demography and Asymmetries». Economic Modelling, 14 (4), 549-65. <http://dx.doi.org/10.1016/S0264-9993(97)00009-6>

HUANG, Haifang y TANG, Yao (2012). «Residential land use regulation and the US housing price cycle between 2000 and 2009». Journal of Urban Economics, 71 (1), 93-99. <http://dx.doi.org/10.1016/j.jue.2011.08.001>

Hubbard, R. Glenn y Mayer, Christopher J. (2009). «The mortgage market meltdown and house prices». The B. E. Journal of Economic Analysis \& Policy, 9 (3), $1-45$. <http://dx.doi.org/10.2202/1935-1682.2223>

HuSSAR, Ave (2014). National Report for Estonia. TENLAW: Tenancy Law and Housing Policy in Multi-level Europe. Recuperado de <http://www.tenlaw.uni-bremen.de/ reports/EstoniaReport_18062014.pdf>. [Consulta: 12 de febrero de 2017]

Huynh-Olesen, Duy; Steiner, Katharina; Hildebrandt, Antje y Wagner, Karin (2013). «Residential property prices in Central, Eastern and Southeastern European Countries: The role of fundamentals and transition-specific factors». En: Mooslechner, Peter y Ritzberger-Grünwald, Doris (eds.). Focus on European Economic Integration Q2/13. Viena: Austrian National Bank, 52-76.

IACOVIELlO, Matteo y NeRI, Stefano (2010). «Housing market spillovers: Evidence from an estimated DSGE model». American Economic Journal Macroeconomics, 2 (2), 125-164. $<$ https://doi.org/10.1257/mac.2.2.125>

IMF (2009). Spain: Selected issues. IMF Country Report 09/129. Washington: International Monetary Fund. 
- (2014). Kingdom of the Netherlands: Netherlands, Selected Issues Paper. IMF Country Report 14/328. Washington: International Monetary Fund.

JAROCINSKI, Marek y SMETS, Frank (2008). House prices and the stance of monetary policy. ECB Working Paper Series, 891. Frankfurt: European Central Bank.

JuD, Donald y WinkLeR, Dan T. (2002). "The dynamics of metropolitan housing prices». Journal of Real Estate Research, 23 (1-2), 29-46.

KARLBERG, Björn y ViCTORIN, Anders (2004). «Housing Tenures in the Nordic Countries». En: LuJANEN Martti (ed.). Housing and Housing Policy in the Nordic Countries. Copenhague: Nordic Council of Ministers, 57-78. <https://doi.org/10.6027/nord2004-007>

KIm, Kyung-Hwan y Renaud, Bertrand (2009). "The Global House Price Boom and Its Unwinding: An Analysis and a Commentary». Housing Studies, 24, 7-24. <http://dx.doi.org/10.1080/02673030802550128>

KnOlL, Katharina; SCHUlarick, Moritz y STEger, Thomas (2017). «No Price Like Home: Global House Prices, 1870-2012». American Economic Review, 107 (2), 331-353.

<http://dx.doi.org/10.1257/aer.20150501>

LAINO, Elsa y PITTINI Alice (2011). Housing Europe review 2012: The nuts and bolts of European social housing systems. Bruselas: Housing Europe, CECODHAS.

LEAmer, Edward E. (2007). Housing Is The Business Cycle. NBER Working Paper 13428. Cambridge, MA: National Bureau of Economic Research.

LEe, Hahn Shik y LEE, Woo Suk (2017). «Housing market volatility connectedness among G7 countries». Applied Economics Letters, 1-6. <http://dx.doi.org/10.1080/13504851.2017.1305069>

LEROY, Stephen y PORTER, Richard (1981). «The present-value relation: Tests base on implied variance bounds». Econometrica, 49 (3), 555-574.

<http://dx.doi.org/10.2307/1911512>

Leung, Frank; CHOW, Kevin y HaN, Gaofeng (2008). Long-term and Short-term Determinants of Property Prices in Hong Kong. Working Paper 15/2008. Hong Kong: Hong Kong Monetary Authority.

LEVINE, Sheen S. y ZAJAC, Edward J. (2007). «The institutional nature of price bubbles». SSRN Electronic Journal. <http://dx.doi.org/10.2139/ssrn.960178>

LeVitin, Adam J. y WaCHTER, Susan M. (2012). «Explaining the Housing Bubble». The Georgetown Law Journal, 100 (4), 1177-1258. <http://dx.doi.org/10.2139/ssrn.1669401>

- (2013). "Why housing?». Housing Policy Debate, 23(1), 5-27. <http://dx.doi.org/10.1080/10511482.2012.749936>

Lily, Chan; TIONG, N. Heng y RAMCHAND, Rishi (2012). «A cluster analysis approach to examining Singapore's property market». BIS Papers, 64, 43-53.

LOUTSKina, Elena y STRAHAN, Philip, E. (2015). «Financial Integration, Housing, and Economic Volatility». Journal of Financial Economics, 115, 25-41. <http://dx.doi.org/10.1016/j.jfineco.2014.09.009>

Lux, Thomas (1995). «Herd behaviour, bubbles and crashes». Economic Journal, 105 (431), 881-896. <http://dx.doi.org/10.2307/2235156>

MaCHADO, José A. y SOUSA, João (2006). Identifying asset price booms and busts with quantile regressions. Estudos e Documentos de Trabalho. Lisboa: Banco de Portugal. 
MADrid, Alberto y Hierro, Luis A. (2015). «Burbujas especulativas: El estado de una cuestión poco estudiada». Cuadernos de Economía, 38 (108), 123-138. <http://dx.doi.org/10.1016/j.cesjef.2015.05.001>

MalpezZI, Stephen y WaCHTER, Susan M. (2005). "The role of speculation in real estate cycles». Journal of Real Estate Literature, 13 (2), 141-164. <http://dx.doi.org/10.2139/ssrn.2585241>

MALZUBRIS, Janis (2008). «Ireland's Housing Market: Bubble Trouble». ECFIN Country Focus, 5 (9), 1-7.

Mayer, Christopher y HubBard, R. Glenn (2009). House Prices, Interest Rates and the Mortgage Market Meltdown. Nueva York: Columbia University.

MCMillen, Daniel P. (2008). "Changes in the distribution of house prices over time: Structural characteristics, neighborhood, or coefficients?». Journal of Urban Economics, 64 (3), 573-589. <http://dx.doi.org/10.1016/j.jue.2008.06.002>

MCQueEN Grant y ThORLeY, Steven (1994). «Bubbles, stock returns and duration dependence». Journal of Financial and Quantitative Analysis, 29 (3), 379-401. $<$ http://dx.doi.org/10.2307/2331336>

MikHED, Vyacheslav y ZEMčíK, Petr (2009). «Do house prices reflect fundamentals?: Aggregate and panel data evidence». Journal of Housing Economics, 18 (2), 140-149. <http://dx.doi.org/10.1016/j.jhe.2009.03.001>

Muellbauer, John y MurPhy, Anthony (2008). «Housing Markets and the Economy: The Assessment». Oxford Review of Economic Policy, 24 (1), 1-33. <http://dx.doi.org/10.1093/oxrep/grn011>

NiEMIETZ, Kristian (2012). Abundance of Land, Shortage of Housing. IEA Discussion Paper 38. Londres: The Institute of Economic Affairs.

NNEJI, Ogonna; BroOKS, Chris y WARD, Charles (2013). «Intrinsic and rational speculative bubbles in the US housing market: 1960-2011». Journal of Real Estate Research, 35 (2), 121-151.

NORRIS, Michelle y SHIELS, Patrick (2004). Regular National Report on housing developments in European countries: Synthesis report. Dublín: The Stationery Office.

PitTINI, Alice; GHeKIÈre, Laurent; DijOL, Julien y Kiss, Igor (2015). The State of Housing in the EU 2015. Bruselas: Housing Europe, CECODHAS.

Planning Authority (2002). Structure Plan for the Maltese Islands: Housing Topic Paper. Floriana: Malta Environment \& Planning Authority.

Posedel, Petra y VizeK, Maruška (2009). «House price determinants in transition and EU-15 countries». Post-Communist Economies, 21 (3), 327-343.

<http://dx.doi.org/10.1080/14631370903090640>

Poterba, James M. (1992). «Taxation and Housing: Old Questions, New Answers». The American Economic Review, 82 (2), 237-242. <http://dx.doi.org/10.3386/w3963>

ROLNIK, Raquel (2013). «Late neoliberalism: The financialization of homeownership and housing rights». International Journal of Urban and Regional Research, 37 (3), 1058-1066. <http://dx.doi.org/10.1111/1468-2427.12062>

RoY, Friedemann (2008). «Mortgage markets in central and eastern Europe: A review of past experiences and future perspectives». European Journal of Housing Policy, 8 (2), 133-160. <http://dx.doi.org/10.1080/14616710802061953> 
RuOnavaAra, Hannu (2012). «Home ownership and the Nordic housing policies in the Retrenchment». En: RonAld, Richard y Elsinga, Marja (eds.). Beyond Home Ownership: Housing, Welfare and Society. Londres: Routledge, 91-107.

SAK, Barbara y RAPONI, Michael (2001). Housing statistics in the European Union 2002. Lieja: International Centre for Research and Information on the Public and Cooperative Economy.

SCAnlon, Kathleen; Fernández-Arrigoitia, Melissa y Whitehead, Christine M. (2015). «Social housing in Europe». European Policy Analysis, 17, 1-12.

SCANLON, Kathleen y WHITEHEAD, Christine M. (2004). International trends in housing tenure and mortgage finance. Londres: The Council of Mortgage Lenders.

SCATIGnA, Michela; SzEMERE Robert y Tsatsaronis, Kostas (2014). «Residential property prices across the globe». En: BORIO, Claudio; DOMANSKI, Dietrich; SHIN, Hyun Song; Turner, Philip y UpPer Christian (eds.). BIS Quarterly Review, September 2014, International banking and financial market developments. Basilea: Bank for International Settlements.

SCherbinA, Anna (2013). Asset Price Bubbles: A Selective Survey. IMF Working Paper 13/45. Washington: International Monetary Fund. <http://dx.doi.org/10.5089/9781475515299.001>

Schwartz, Herman M. y SEabrooke, Leonard (eds.) (2009). The Politics of Housing Booms and Busts. Hampshire: Palgrave MacMillan. <http://dx.doi.org/10.1057/9780230280441>

SEYFRIED, William (2010). «Monetary policy and housing bubbles: A multinational perspective». Research in Business \& Economic Journal, 2, 1-12.

Shelburne, Robert C. y PAlacin, José (2006). «Is There an East European Housing Bubble?». Global Economy Journal, 6 (3), 1-37. <https://doi.org/10.2202/1524-5861.1209>

SHILLER, Robert (1981). «Do stock prices move too much to be justified by subsequent changes in dividends». American Economic Review, 71, 421-436.

- (2005). Irrational Exuberance. Nueva York: Princeton University Press. <http://dx.doi.org/10.1515/9781400865536>

Sowell, Thomas (2009). The Housing Boom and Bust. Nueva York: Basic Books.

Stepanyan, Vahram; Poghosyan, Tigran y Bibolov, Aidyn (2010). House price determinants in selected countries of the former Soviet Union. IMF Working Paper 10/104. Washington: International Monetary Fund. <http://dx.doi.org/10.5089/9781455200634.001>

STEPHENS, Mark (2007). "Mortgage market deregulation and its consequences». Housing Studies, 22 (2), 201-220. <http://dx.doi.org/10.1080/02673030601132797>

SVEINSSON, Jón Rúnar (2010). «Kreppa, hugmyndafræði og félagslegt húsnæði». Íslenska pjóðfélagið, 1 (1), 49-67.

TAYLOR, John B. (2009). Getting off track: How government actions and interventions caused, prolonged, and worsened the financial crisis. Stanford: Hoover Institution Press.

Terrones, Marco y OTroK, Christopher (2004). "The global house price boom». En: IMF (2004). World Economic Outlook, the Global Demographic Transition, September 2004. Washington: International Monetary Fund, 71-89.

Tirole, J. (1985). «Asset bubbles and overlapping generations». Econometrica, 53 (5), 1071-1100.

<http://dx.doi.org/10.2307/1911012> 
Torrero, Antonio (2008). La crisis financiera internacional. Documentos de trabajo 08/2008, Alcalá de Henares: Instituto Universitario de Análisis Económico y Social. Universidad de Alcalá.

TSATSARONis, Kostas y ZHU, Haibin (2004). «What drives housing price dynamics: Cross-country evidence». En: Bisignano, Joseph; Remolona, Eli; White, William; Borio, Claudio; Turner, Philip; MCCauley, Robert y Van DeN BERGH, Paul (eds.). BIS Quarterly Review, March 2004, International banking and financial market developments. Basilea: Bank for International Settlements.

VALADEZ, Ray M. (2011). "The housing bubble and the GDP: A correlation perspective». Journal of Case Research in Business and Economics, 3, 1-18.

Van Nieuwerburgh, Stijn y Weill, Pierre Olivier (2010). "Why has House Price Dispersion Gone Up?». Review of Economic Studies, 77 (4), 1567-1606. <https://doi.org/10.1111/j.1467-937X.2010.00611.x>

VERMEULEN, Wouter y RouWENDAL, Jan (2007). Housing supply and land use regulation in the Netherlands. Discussion Paper 07-058/3. Amsterdam y Rotterdam: Tinbergen Institute.

Wallison, Peter J. (2009). "Cause and effect: Government policies and the financial crisis». Critical Review, 21 (2-3), 365-376. <http://dx.doi.org/10.1080/08913810902934158>

WEST, Kenneth (1987). «A specification test for speculative bubbles». The Quarterly Journal of Economics, 102 (3), 553-580. <https://doi.org/10.2307/1884217>

ZieTZ, Joachim; ZIETZ, Emily Norman y SiRMANS, G. Stacy (2008). «Determinants of house prices: A quantile regression approach». The Journal of Real Estate Finance and Economics, 37 (4), 317-333.

<https://doi.org/10.1007/s11146-007-9053-7> 